Ann. Zootech., I964, $13(2)$, II7-I5O.

\author{
I.N.R.A. \\ BibliotheQUE UO 35906 \\ Domaine oe Crouelle \\ 63039 \\ Clermont-FD Cedex?
}

\title{
DIGESTIBILITÉ DES CONSTITUANTS DU RAY-GRASS ANGLAIS S 24 ET DU DACTYLE S 37, PLUS SPÉCIALEMENT DES CONSTITUANTS GLUCIDIQUES
}

\author{
R. JARRIGE et D. J. MINSON \\ Station dc Recherches sur l'élevage des Ruminanis, \\ Ceutre national de Recherches zooterhniques, Jouy-en-Josas (Seine-et-Oise) \\ The Grassland Research Institute Hurley, (Grande-Bretagne) \\ avec la collaboration technique de Marie-Thérèse BEaufort et Janine Jung
}

\section{SOMMAIRE}

Soixante deux échantillons de ray-grass $\mathrm{S}_{24}$ et de dactyle $\mathrm{S}_{37}$, ainsi que les échantillons de fèces correspondants, ont été analysés de façon relativement complète afin de comparer la digestibilité des différents constituants, des constituants glucidiques plus spécialement, et d'expliquer les variations du coefficient de digestibilité de la plante entière. L'ensemble des constituants déterminés représente en moyenne $84 \mathrm{p}$. Ioo de la matière sèche des fourrages et $86 \mathrm{p}$. roo de celle des fèces.

Les différents constituants glucidiques, qui représentent ensemble de 37 à 68 p. Ioo du fourrage, n'ont pas la même digestibilité. Les glucides solubles sont entièrement digestibles et la lignine ne l'est pratiquement pas, en moyenne tout au moins. Les polysaccharides de la membrane ont une digestibilité très variable (en gros de 45 à 95 p. I00) notamment au cours du $\mathbf{I}^{\text {er }}$ cycle de croissance. La fraction hémicelluloses est significativement moins digestible que la fraction cellulose, de 6 à 9 points en général, parce qu'elle contient la majeure partie des xylanes ( 88 p. Ioo en moyenne) qui ont été les polysaccharides les moins digestibles de la membrane dans les i6 échantillons où ils ont été déterminés.

Le coefficient de digestibilité des polysaccharides de la membrane présente une liaison négative extrêmement étroite avec la teneur en lignine qui semble bien en être le facteur principal. Eille présente également une liaison négative étroite avec la teneur elle-même des polysaccharides, de telle sorte que la teneur en polysaccharides membranaires digestibles (hémicelluloses digestibles + cellulose digestible) est relativement peu variable : elles est de l'ordre de $30 \mathrm{p} .100$ dans la plupart des plantes étudiées.

La digestibilité de la plante dépend avant tout, et presque exclusivement, de la digestibilité des polysaccharides de la membrane. C'est pourquoi elle demeure très élevée jusqu'à l'épiaison et diminue ensuite très rapidement au cours du premier cycle ; c'est aussi pourquoi, à proportion de limbes égale, elle est plus élevée pour les plantes du premier cycle que pour les repousses d'une part, pour le ray-grass $S_{24}$ que pour le dactyle $S_{37}$, d'autre part. Cependant, les variations très importantes de la teneur en glucides solubles (de I, 6 à 21, 5 p. Ioo) introduisent certaines modifications annexes de la digestibilité qui, d'une façon générale, tendent à accroître les différences précédentes. 


\section{INTRODUC'TION}

I a teneur en matière organique digestible est le principal facteur de la valeur énergétique nette des plantes fourragères. Elle varie dans des limites très larges comme on l'a montré notamment pour la fléole et le trèfle violet (HoMB, I953; KIVIMAE, I959), la luzerne (Drjkstra et BRANDSMa, I955), le ray-grass anglais et le dactyle (MINSON, RAyMond et HARris, I960). Elle dépend d'abord de la composition morphologique de la plante caractérisée par la proportion de limbes foliaires, mais elle n'en dépend pas exclusivement. Ainsi, à proportion de limbes comparable (fig. I), les graminées du $\mathrm{I}^{\mathrm{er}}$ cycle étudiées par MrNson et al. ont été plus digestibles que les repousses correspondantes; de même le ray-grass S 24 a été systématiquement plus digestible que le dactyle $\mathrm{S} 37$.

C'est pour expliquer ces différences et d'une façon plus générale, pour interpréter les variations de la digestibilité de ces deux plantes, que nous avons analysé de façon approfondie un certain nombre d'échantillons ainsi que les échantillons de fèces correspondants. Nous nous sommes plus particulièrement attachés à déterminer la teneur et la digestibilité des principaux constituants glucidiques qui représentent de 37 à 68 p. Ioo de la matière sèche des fourrages étudiés. Elles étaient jusqu'ici mal connues parce que plus de la moitié de ces constituants passent dans la fraction indéterminée, ou extractif non azoté, de la méthode d'analyse classique.

Nous rapportons ici les résultats détaillés de cette étude dont un premier aperçu a déjà été publié (JARRige, I960).

\section{MATÉRIEI, ET MÉTHODES}

\section{Échantillons}

On a étudié 30 échantillons de ray-grass $\mathrm{S} 24$ et 32 échantillons de dactyle $\mathrm{S} 37$ choisis respectivement parmi les $4 \mathrm{I}$ et les 44 échantillons dont MiNSON et al. (I960) ont mesuré la digestibilité et publié les principales caractéristiques : conditions de croissance, production, pourcentage de limbes, teneurs en azote, en cendres et en matière organique digestible (D). Il s'agit là d'un ensemble trèreprésentatif des plantes coupées à différents stades au cours du i ${ }^{\text {er }}$ cycle $\left(3^{2}\right)$ et des repousses prélevées de juin à novembre, à l'âge de un mois (18) ou de deux mois (6).

Ces fourrages ont été récoltés à Hurley au cours de deux années consécutives : 1958 dont l'été fut très pluvieux et I 959 dont l'été fut, au contraire, très sec. Ils ont été portés à la chambre froide immédiatement après la fauche et leur digestibilité al été mesurée sur trois moutons (RAYMond et al., 1953) pendant des périodes expérimentales de douze jours. Des échantillons moyens de fourrages et de féces ont été préparés pour l'analyse.

Pour l'interprétation des résultats, il est nécessaire de rappeler la date du début de l'épiaison : I3 mai 1958 et 9 mai 1959 pour le ray-grass $S_{24}$, I3 mai $195^{8}$ et ro mai 1959 pour le dactyle $S_{37}$.

\section{Analyse}

Les teneurs en cendres et en matières azotées ont été déterminées à Hurley, et les autres constituants à Jouy-en-Josas. Les constituants glucidiques ont été séparés et dosés suivant la méthode proposée et discutée par JARRIGE (I96I-I963); les glucides solubles, les hémicelluloses et la cellulose 
ont été estimés successivement par le pouvoir réducteur (SOMOGYI, I952) de l'extrait aqueux de l'hydrolysat par $\mathrm{SO}_{2} \mathrm{H}_{4}$ à $5 \mathrm{p}$. Ioo et de l'hydrolysat par $\mathrm{SO}_{2} \mathrm{H}_{4}$ à $72 \mathrm{p}$. 100. De la lignite brute obtenue à l'issue de ces traitements, on a soustrait la teneur en matières azotées $(\mathrm{N} \times 6,25)$ qui a été soit déterminée directement, soit estimée à partir de la teneur en matières azotées du fourrage ou des fèces (JOURNET et JARRIGE, I962).

Sur les échantillons de fourrage de $195^{8}$, on a dosé séparément les sucres extraits par l'alcool à $80 \mathrm{p}$. 100 et les fructosanes extraits ensuite par l'eau à $40^{\circ}$. Cette séparation n'a pas été poursuivie pour les fourrages de 1959 quand il s'est avéré que les deux catégories de glucide solubles étaient entièrement digestibles, et que l'estimation globale donnait sensiblement les mêmes résultats que la somme des déterminations séparées.

On a déterminé les principaux sucres des hydrolysats $5 \mathrm{p}$. Ioo (hémicelluloses) et $7^{2} \mathrm{p}$. Ioo (cellulose) de huit échantillons de chaque espèce ainsi que des échantillons de fèces correspondants : quatre plantes prélevées au cours du $\mathrm{I}^{\mathrm{er}}$ cycle, deux repousses âgées de un mois et deux repousses âgées de deux mois. Après séparation chromatographique sur papier, on a dosé le xylose, l'arabinose et la somme glucose plus galactose de l'hydrolysat $5 \mathrm{p}$. Ioo, le xylose et le glucose de l'hydrolysat 72 p. 100.

\section{RÉSUL'TATS}

La teneur des différents constituants est présentée dans les tableaux I à 4 , et leur digestibilité dans les tableaux 5 à 8 .

\section{CONSTITUANTS CYTOPLASMIQUES}

\section{Matières azotées}

La proportion de limbes a été le facteur principal de la teneur en matières azotées (fig. 2) et a expliqué notamment la diminution rapide de celle-ci au cours du I er cycle, et son augmentation dans les repousses d'automne. Cependant, à proportion de limbes donnée, la teneur en matières azotées a présenté des variations parfois importantes, associées aux conditions climatiques, au vieillissement (repousses de deux mois) et à l'espèce : ainsi, elle a été généralement plus élevée pour les repousses de dactyle que pour celles de ray-grass.

I e coefficient de digestibilité apparent des matières azotées a varié dans le même sens que la teneur, suivant la loi curvilinéaire classique. A teneur égale il a été, en général, sensiblement plus élevé pour le ray-grass que pour le dactyle, tout au moins pour les plantes contenant plus de I5 p. Ioo de matières azotées.

\section{Glucides solubles}

La teneur en glucides solubles dans l'eau (sucres + fructosanes) a relativement peu varié au cours du $\mathbf{I}^{\mathrm{er}}$ cycle de croissance de chacune des deux espèces ; cependant en I958 elle a été maximum juste avant la floraison, et en I959 elle a été minimum au début de la croissance. La teneur des repousses a été nettement plus faible que celle des plantes du I $^{\text {er }}$ cycle et a présenté des valeurs minimum en août-septembre (tab1. 3 et 4 ); elle a été systématiquement plus faible en I958 qu'en I959. A date équivalente, le ray-grass a toujours contenu plus de sucres, de fructosanes, de glucides solubles (de 1'ordre de 5 points de plus), que le dactyle. Au total, la teneur en glucides solubles a varié de I,6 p. Ioo à 2 I,5 p. Ioo. 


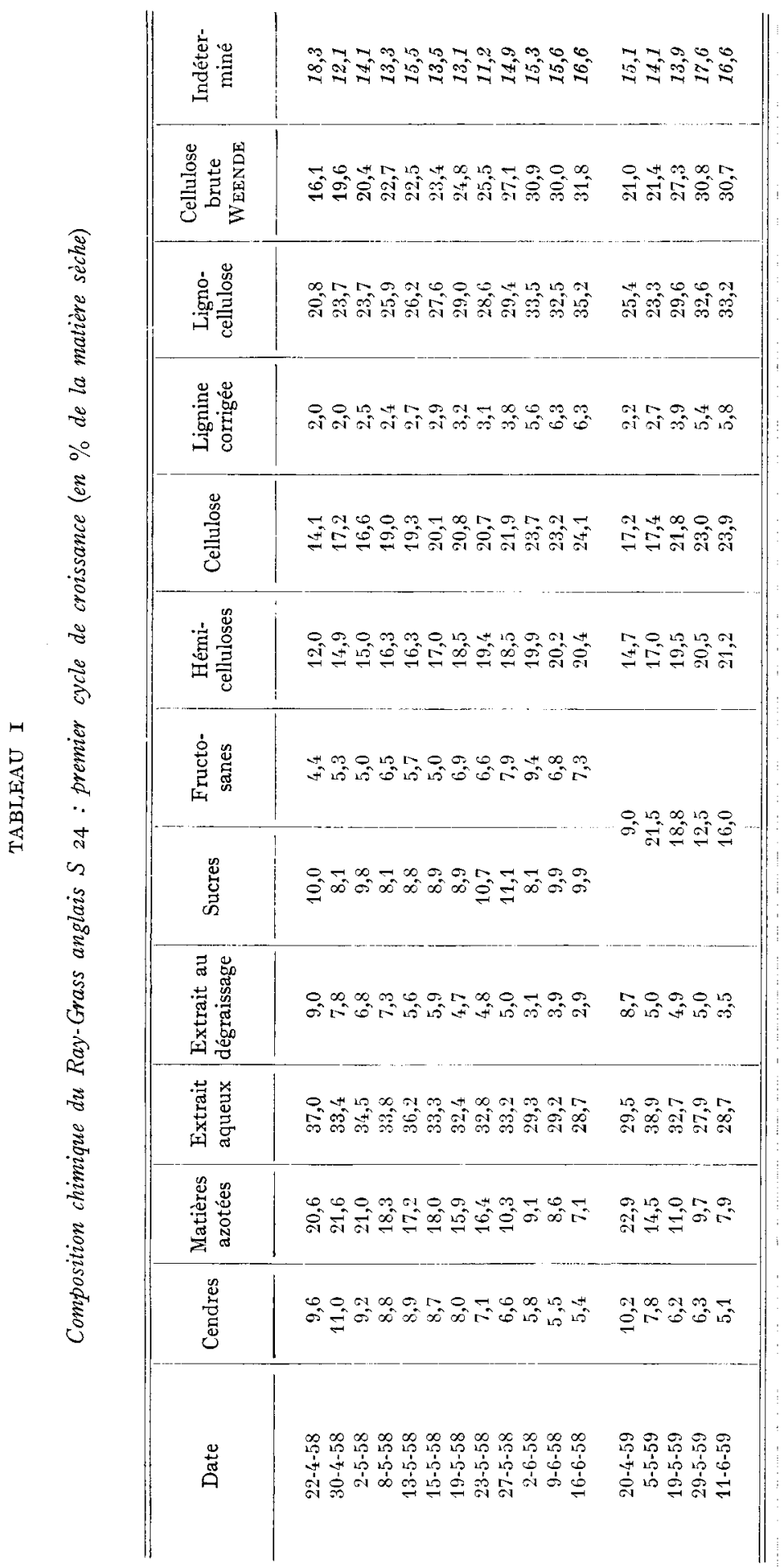




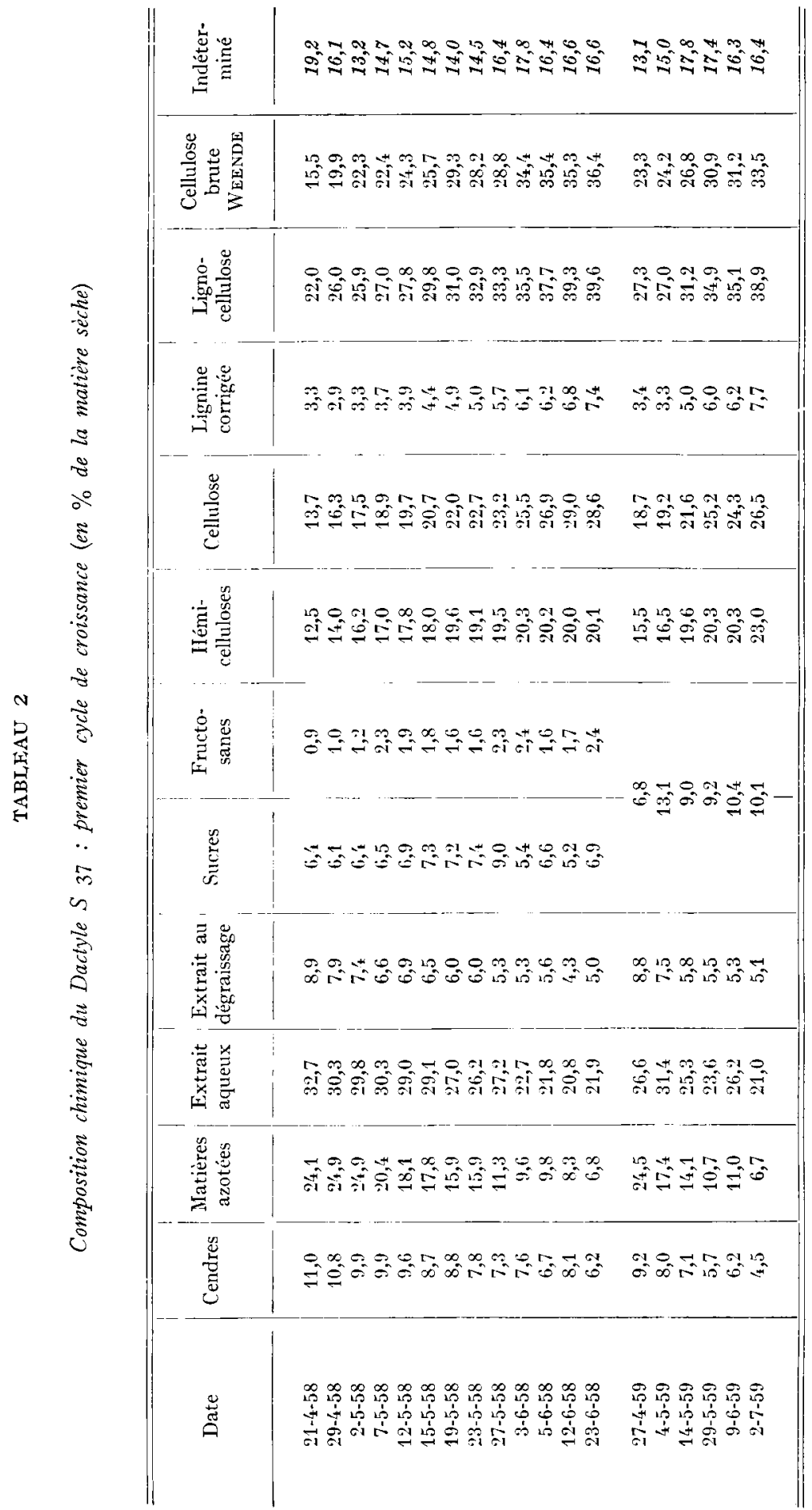


Les extraits aqueux ou les extraits alcooliques des 34 échantillons de fèces examinés, ont eu un pouvoir réducteur extrêmement faible après hydrolyse, qui n'est d'ailleurs peut-être pas dû à des sucres. Le coefficient de digestibilité des glu-

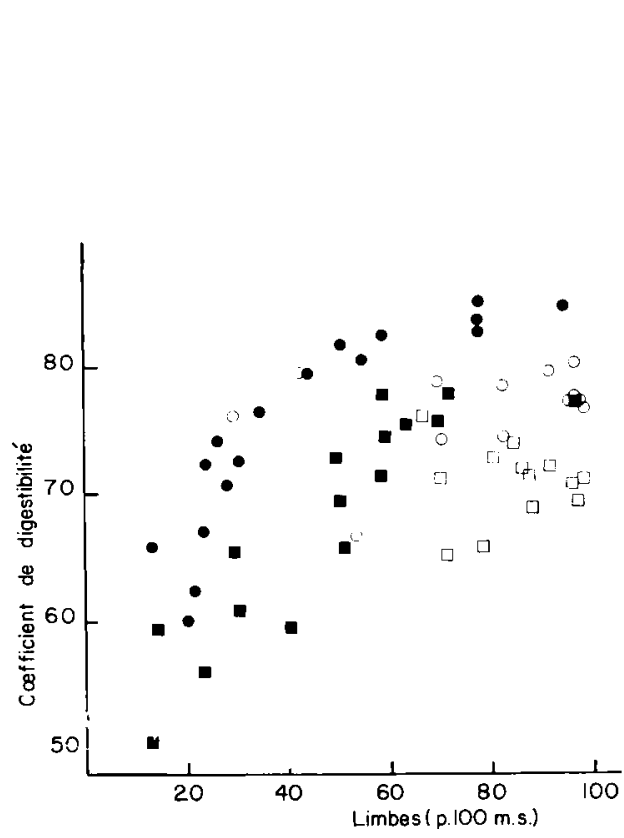

FIG. I. - Relations entre la digestibilité de la matière organique et la proportion de limbes

- Ray-grass S $24:$ q" cycle $^{\prime \prime}$ O Ray-grass $S 24$ : repousses

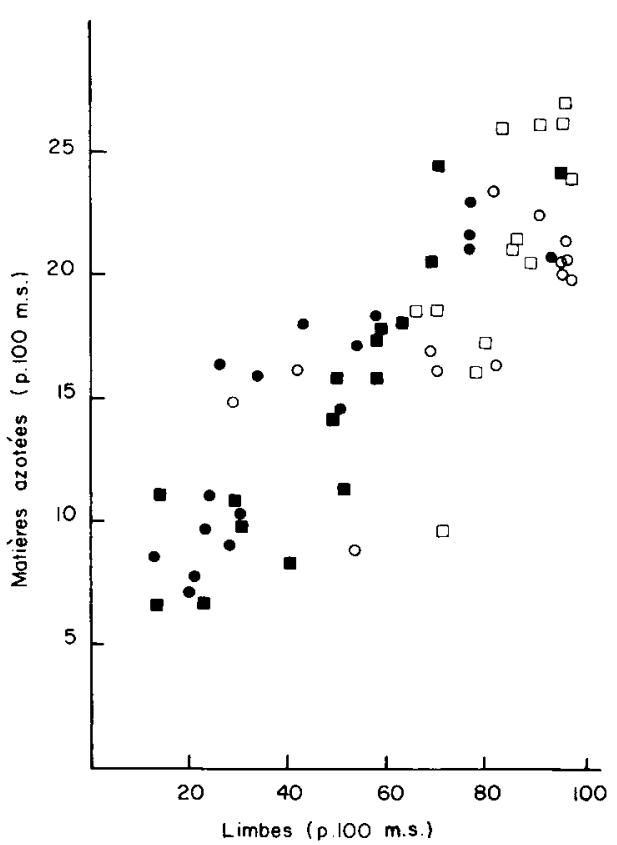

FIG. 2. - Relations entre la teneur en matières asotées et la proportion de limbes

- Dactyle 537 : $\boldsymbol{1}^{* \mathrm{r}}$ cycle 口 Dactyle 537 : repousses

cides solubles a donc été généralement compris entre 99 et roo p. Ioo, de telle sorte qu'on ne l'a pas déterminé sur les autres échantillons et qu'on peut considérer que les glucides solubles sont entièrement digestibles.

\section{Autres extractifs}

La teneur en constituants solubles dans l'eau, autres que les glucides, a diminué au cours du i er cycle de croissance, passant de $25 \mathrm{p}$. Ioo à moins de $15 \mathrm{p}$. Ioo de la matière sèche ; elle a été de l'ordre de 20 p. Ioo dans la majeure partie des repousses âgées d'un mois. I,e coefficient de digestibilité de cette fraction a toujours été plus élevé que celui de la matière organique (en moyenne de 8,3 points), et a varié dans le même sens que ce dernier ; il a présenté des valeurs comparables chez le ray-grass et le dactyle $(85 \mathrm{p}$. Ioo en moyenne dans les repousses mensuelles).

La fraction extraite par le mélange alcool-benzène (lipides — pigments...) après l'extraction aqueuse, a représenté de 3 à 9 p. Ioo de la matière sèche ; elle a varié grossièrement dans le même sens que la teneur en matières azotées, et a notamment 


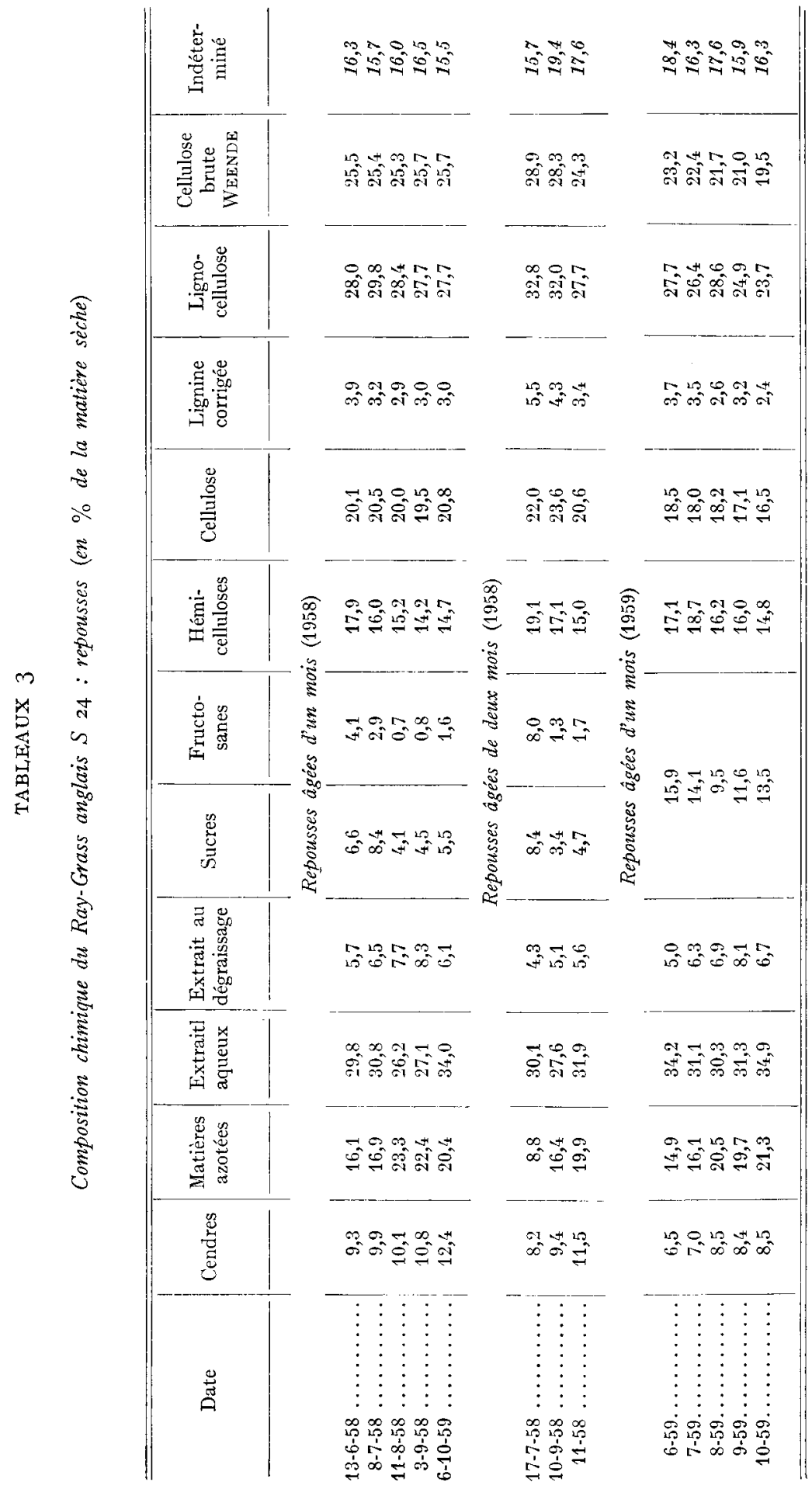


R. JARRIGE, D. J. MINSON

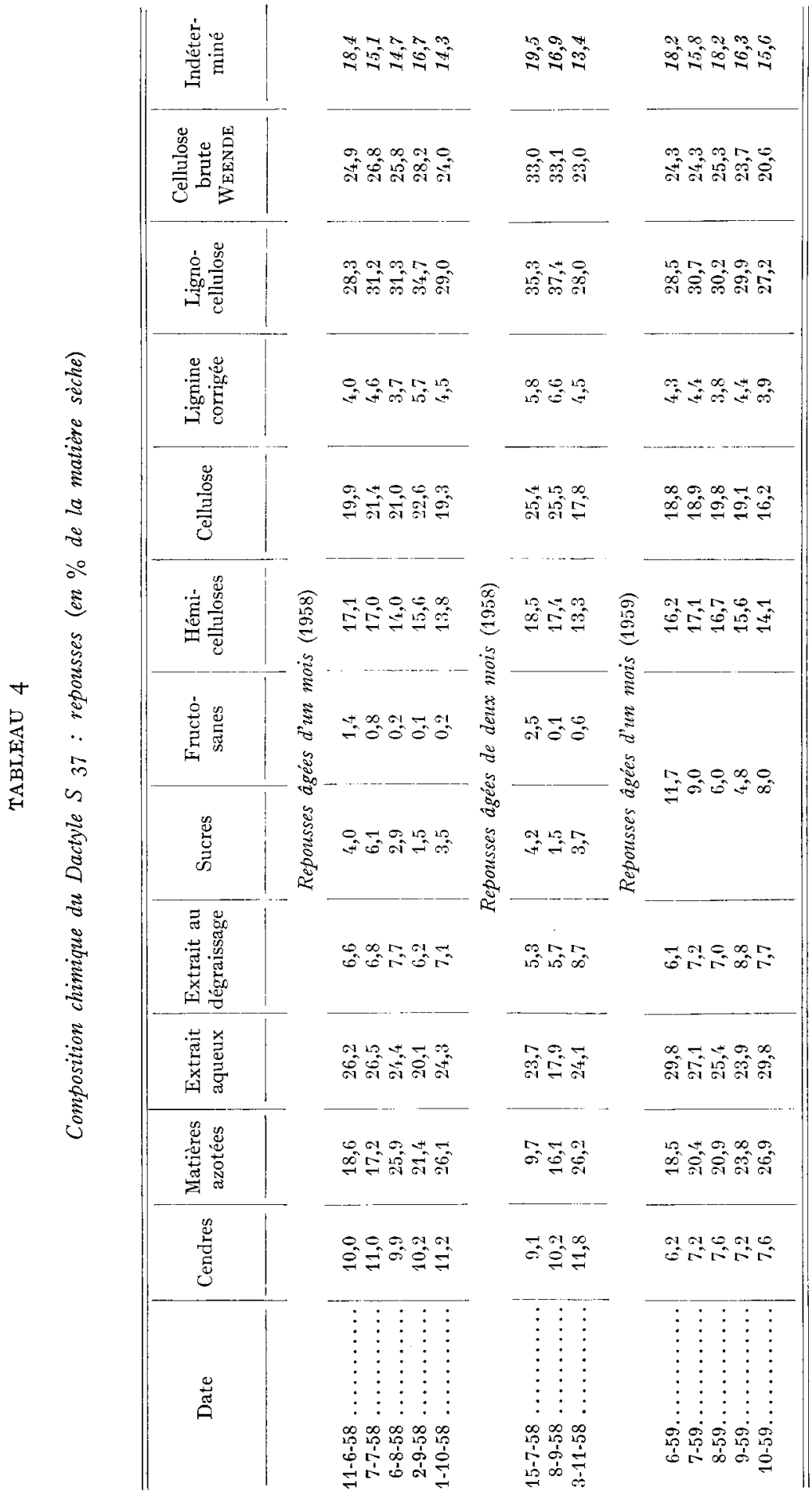


diminué au cours du I er cycle de croissance; elle a été en général un peu plus élevée chez le dactyle que chez le ray-grass. Le coefficient de digestibilité de cette fraction mal définie a été le plus souvent compris entre 45 et 70 p. I00; il a été sensiblement plus élevé chez le ray-grass que chez le dactyle, et a présenté des fluctuations assez irrégulières et pas d'évolution très nette : il a été cependant plus faible à la fin du I $^{\text {er }}$ cycle d'une part, et dans les repousses d'automne d'autre part.

\section{CONSTITUANTS DE LA MEMBRANE}

\section{Hémicelluloses et cellulose}

Les teneurs en hémicelluloses et en cellulose ont présenté des valeurs minimum au début de la croissance; elles ont augmenté au cours du I ${ }^{\text {er }}$ cycle en même temps que la proportion de gaines et de tiges, mais plus lentement à partir d'une date située environ trois semaines après le début de l'épiaison. Elles ont été moins variables dans les repousses mensuelles, mais ont eu tendance à diminuer en automne.

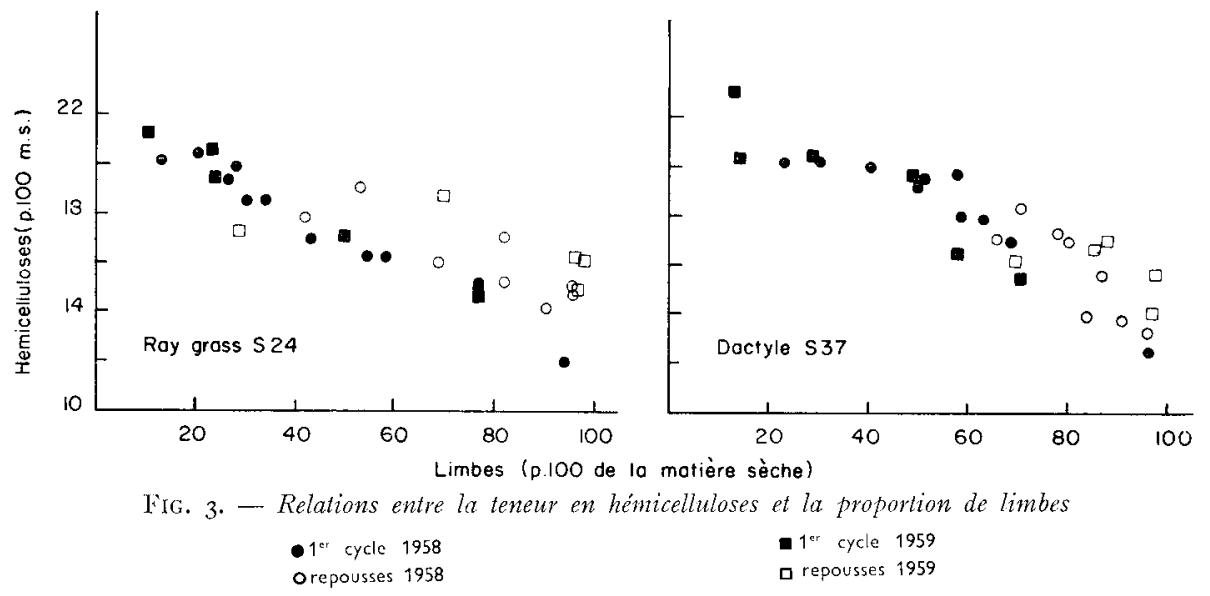

La teneur en hémicelluloses a varié approximativement en sens inverse de la proportion de limbes (fig. 3). Cette relation a été relativement semblable pour les plantes du $\mathrm{I}^{\mathrm{er}}$ cycle et pour les repousses, mais sensiblement différente entre les deux espèces ; en effet, lorsque la proportion de limbes a été inférieure à 50 p. IOo, après l'épiaison, la teneur en hémicelluloses a augmenté de façon très limitée chez le dactyle, et de façon accrue chez le ray-grass. A proportion de limbes égale, le ray-grass a contenu moins d'hémicelluloses que le dactyle, sauf à la fin du $I^{\text {er }}$ cycle. La teneur en cellulose a présenté avec la proportion de limbes une liaison moins étroite que la teneur en hémicelluloses (comparer les figures 3 et 4 ) ; à proportion de limbes égale elle a été beaucoup plus élevée dans les repousses que dans les plantes du I ${ }^{\text {er }}$ cycle d'une part, chez le dactyle que chez le ray-grass d'autre part.

Les coefficients de digestibilité des hémicelluloses et de la cellulose ont varié de façon sensiblement parallèle, dans des limites très grandes : de 52,5 à 90,9 p. Ioo et de 46,4 à 96,7 p. Ioo respectivement. I a cellulose a été pratiquement toujours plus 
R. JARRIGE, D. J. MINSON

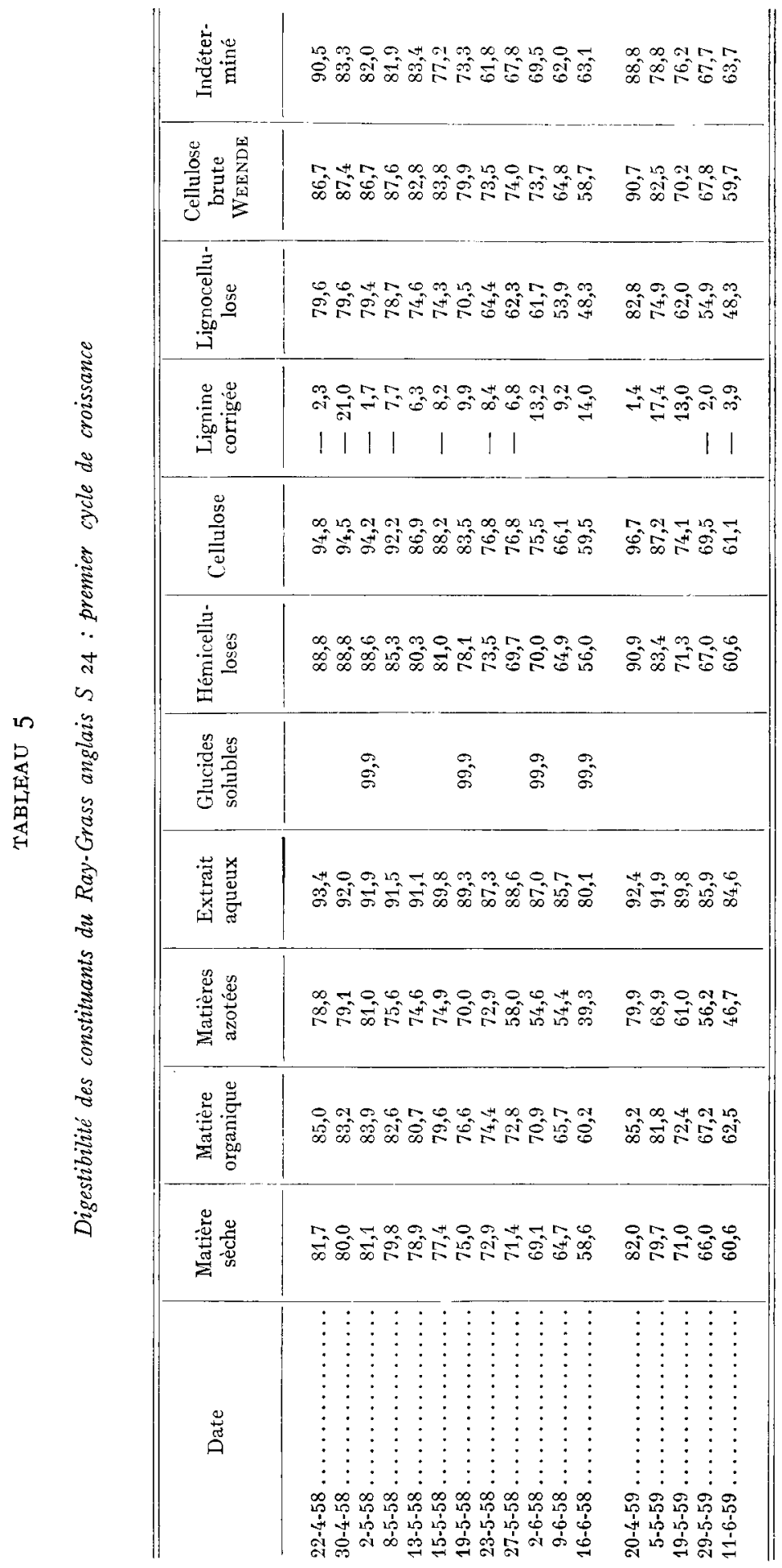




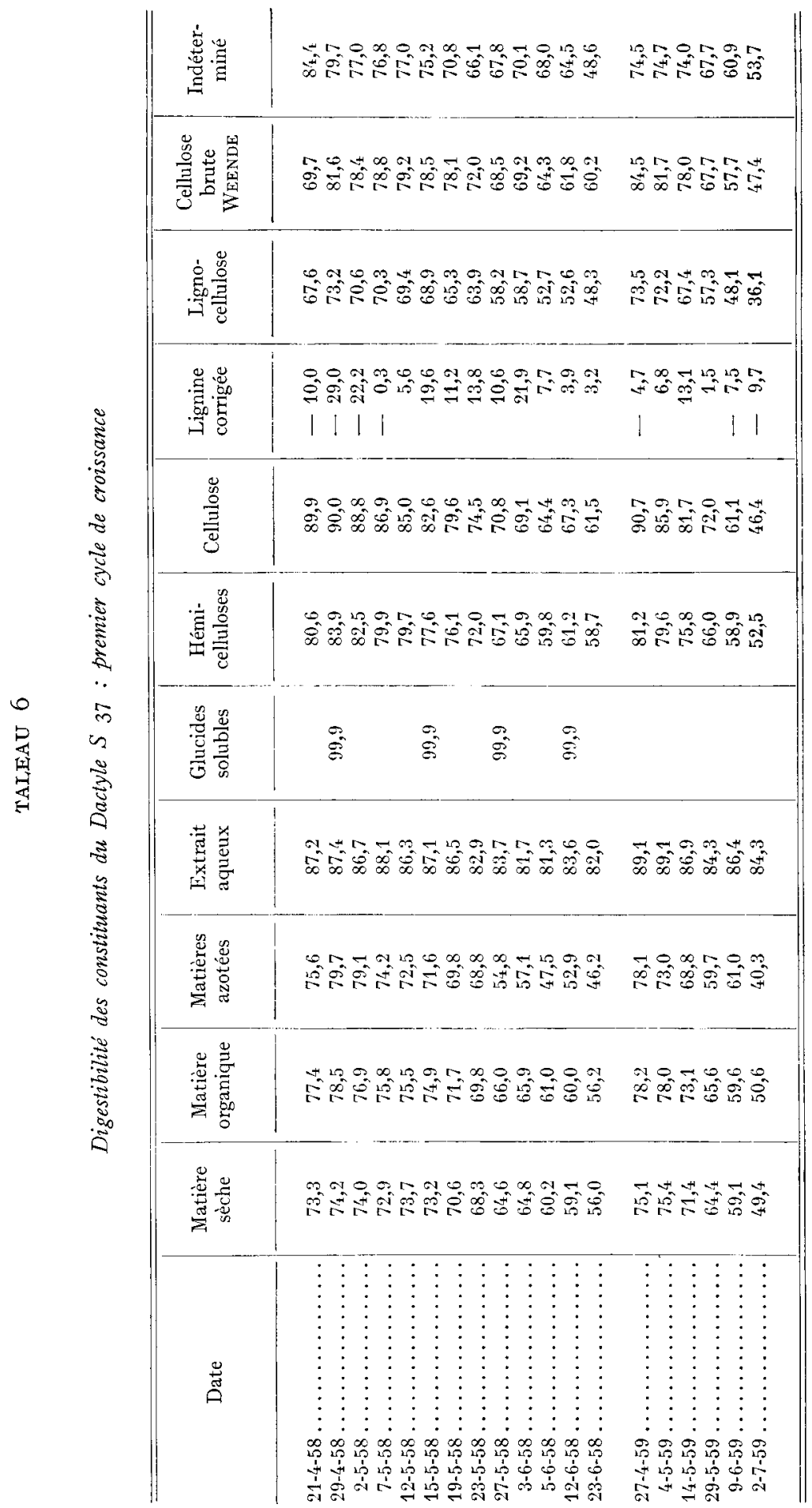




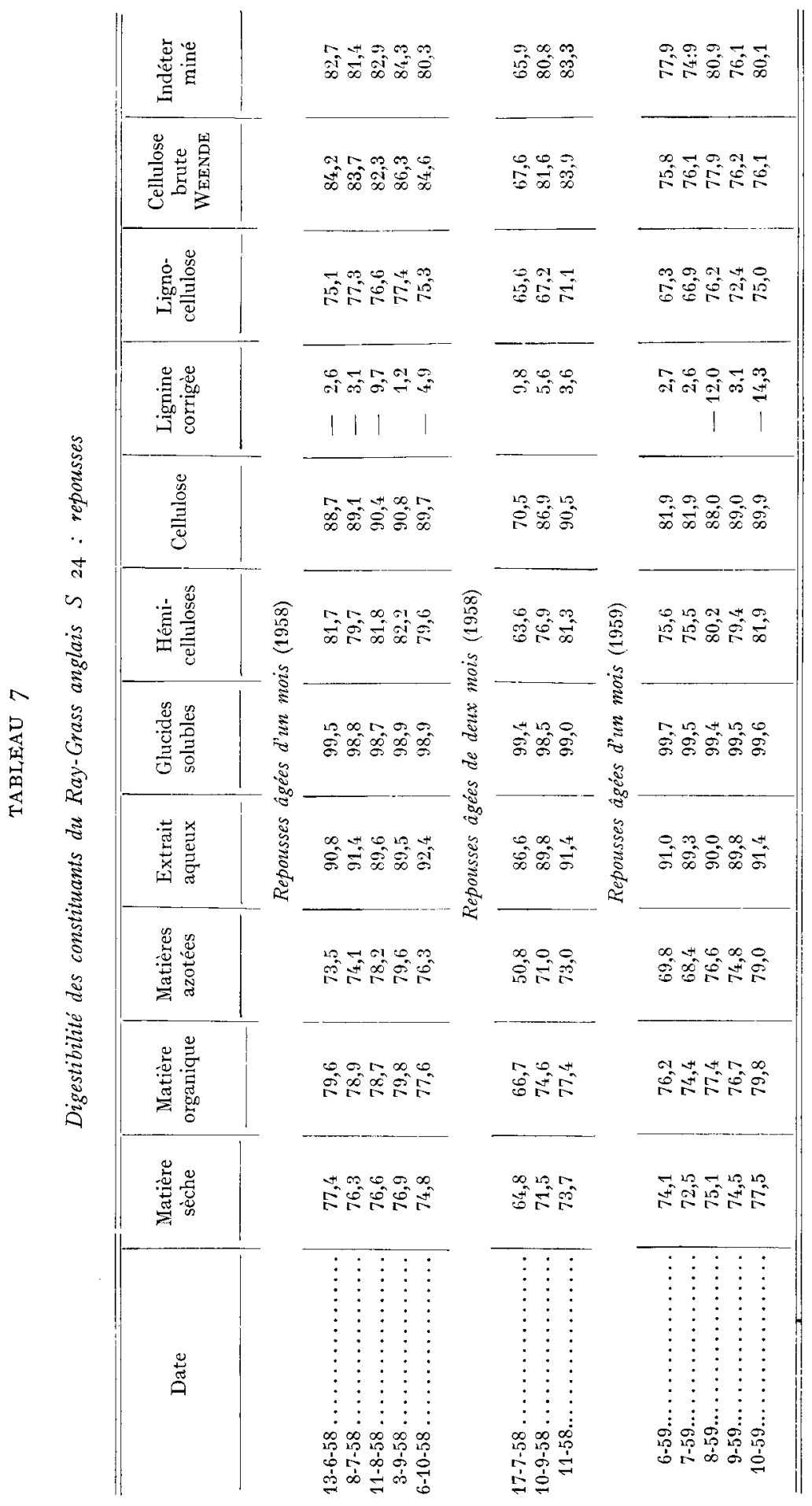




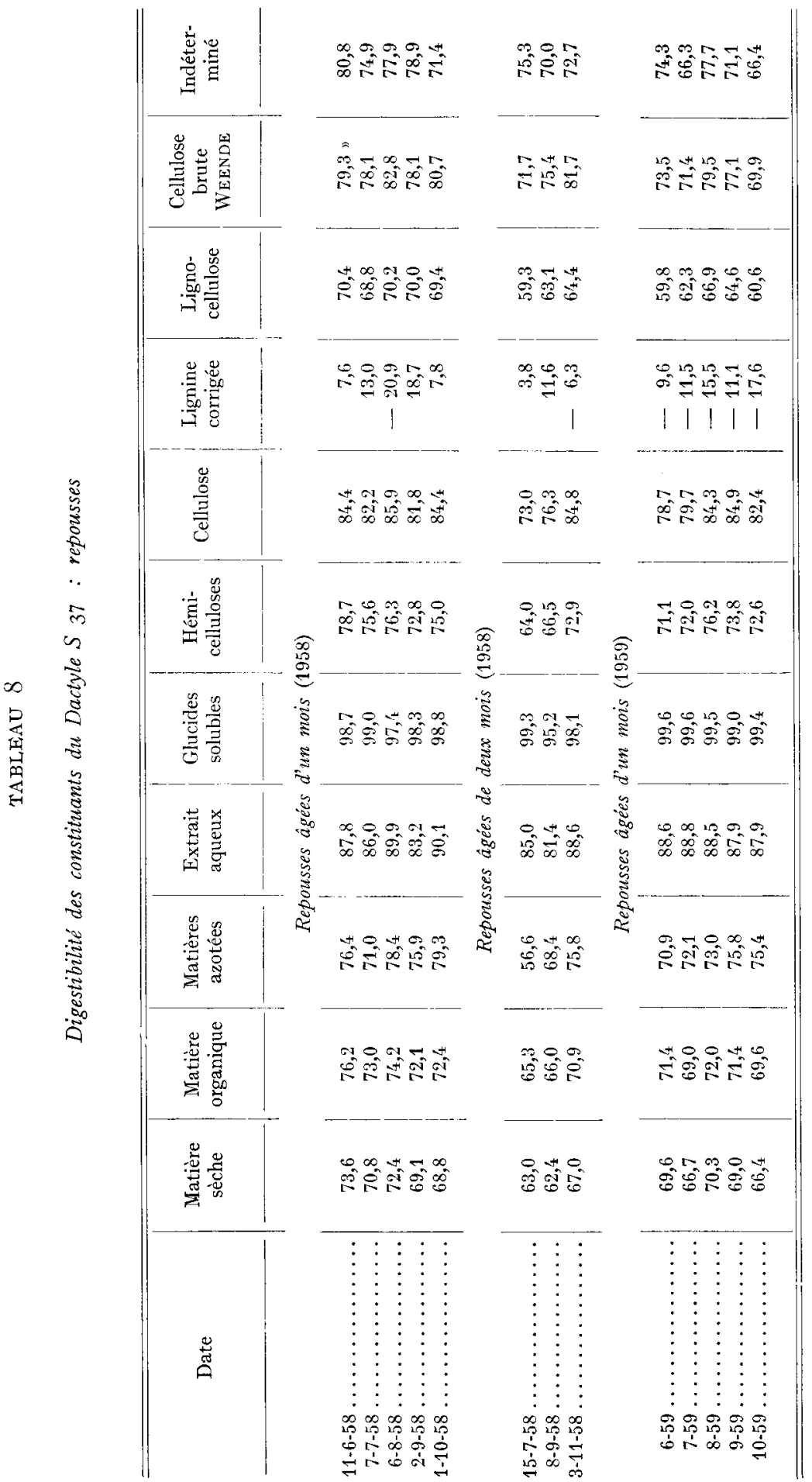


digestible que les hémicelluloses (dans $6 \mathrm{I}$ cas sur 62 ), en moyenne de 6,4 points pour le ray-grass et de 8,6 points pour le dactyle, cette différence ayant eu tendance à diminuer en même temps que la proportion de limbes. A date de récolte ou à proportion de limbes comparables, les hémicelluloses et la cellulose du ray-grass ont été systématiquement plus digestibles que celles du dactyle : la différence a été en moyenne de 7,3 et de 5 ,I points respectivement.

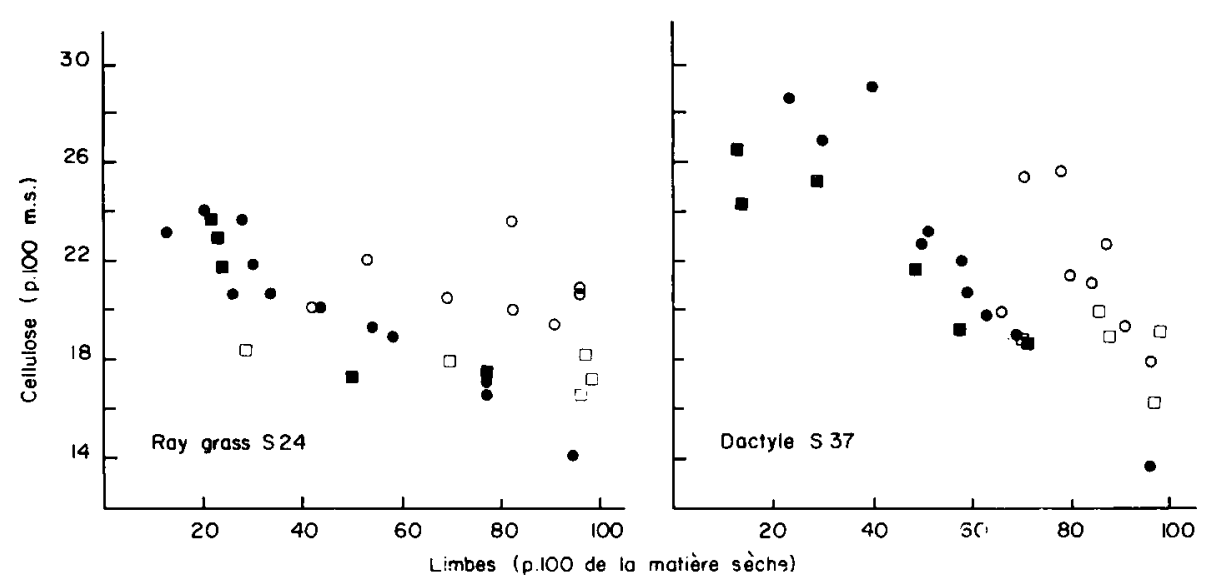

Fig. 4. - Relations entre la teneur en cellulose et la proportion de limbes

$$
\begin{array}{ll}
-1^{\prime \prime} \text { cycle } 1958 & \text { - } 1^{\text {tr }} \text { cycle } 1959 \\
\text { orepousses } 1958 & \text { a repousses } 1959
\end{array}
$$

La digestibilité de la cellulose est demeurée approximativement constante et extrêmement élevée au début $\mathrm{d} \mathrm{I}^{\mathrm{er}}$ cycle (près de $95 \mathrm{p}$. Ioo chez le ray-grass et de 90 p. Ioo chez le dactyle), jusqu'à une date située un peu avant l'épiaison, tant que la proportion de limbes a été supérieure à 70 p. 100 (fig. 5) ; elle a ensuite diminué de façon grossièrement linéaire. La digestibilité des hémicelluloses a évolué de la même façon que celle de la cellulose au cours du $\mathrm{I}^{\text {or }}$ cycle, mais la différence entre les deux a plutôt diminué avec l'âge aussi bien chez le ray-grass que chez le dactyle. La digestibilité de la cellulose et des hémicelluloses des repousses âgées d'un mois a été généralement élevée (de 82 à gr p. roo pour la cellulose du ray-grass et de 79 à 86 p. Ioo pour celle du dactyle) ; elle a varié presque indépendamment de la proportion de limbes, mais a été toujours plus élevée en I959 qu'en 1958 , cle juin à aôtt.

A proportion de limbes égale, les hémicelluloses et la cellulose ont été moins digestibles dans les repousses que dans les plantes du I $^{\text {er }}$ cycle (fig. 5 et 6 ), sauf pour trois repousses de juin sur quatre. La différence a été particulièrement importante pour les repousses de juillet et de septembre $195^{8}$, âgées de deux mois.

\section{Polysaccharides séparés}

Les teneurs en xylanes, arabanes et hexosanes hydrolysables (glucosane + galactane) constituant la fraction hémicelluloses, et en xylanes résiduels et en glucosane (cellulose vraie) constituant la fraction cellulose, ont été déterminées sur huit échantillons de chacune des deux espèces (tabl. 9 et Io). 


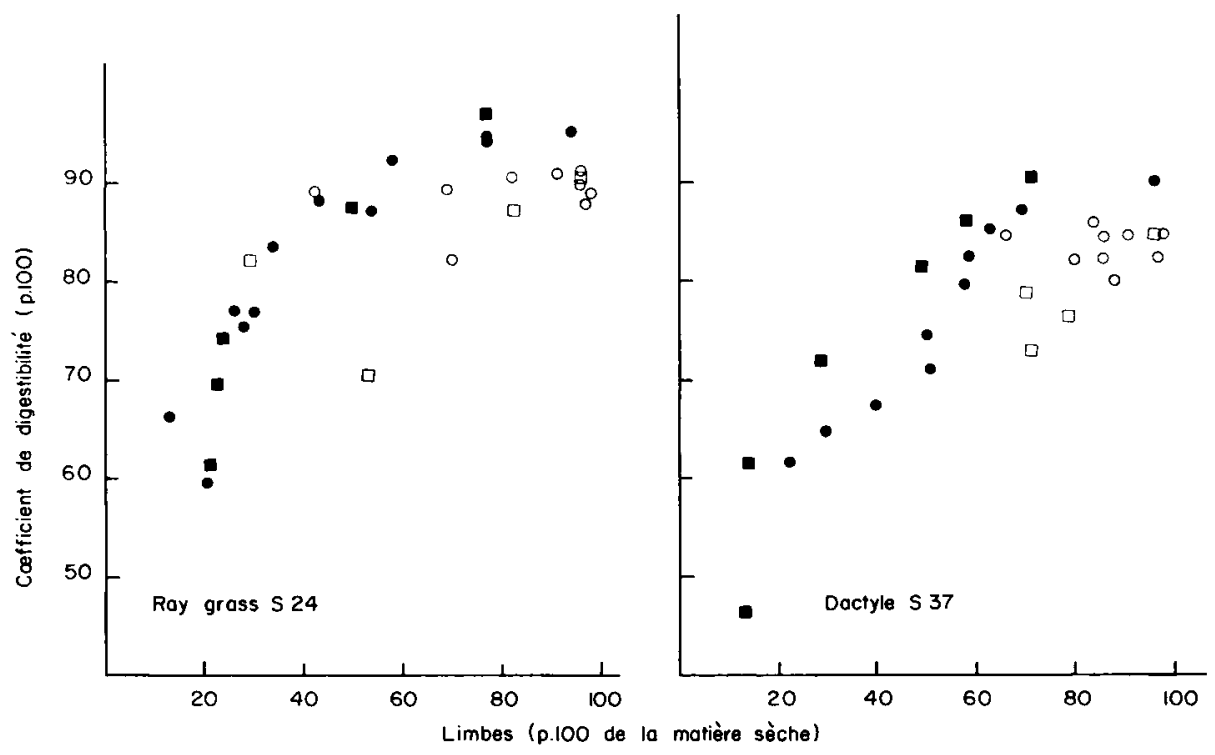

FIG. 5. - Relations entre le coefficient de digestibilité de la cellulose et la proportion de limbes

- 1er cycle 1958

o repousses 1958
- 1*r cycle 1959

a repousses 1959

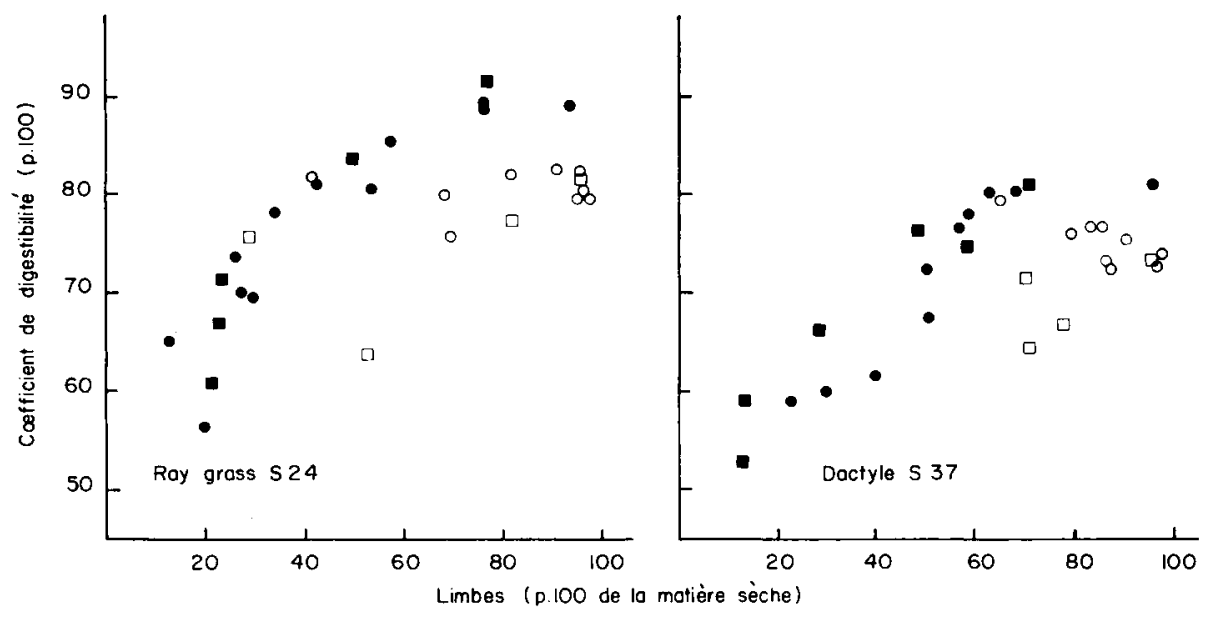

FIG. 6. - Relations entre le coefficient de digestibilité des hémicelluloses et la proportion de limbes

- 16: cycle 1958

Orepousses 1958 -10r cycle 1959

a repousses 1959 

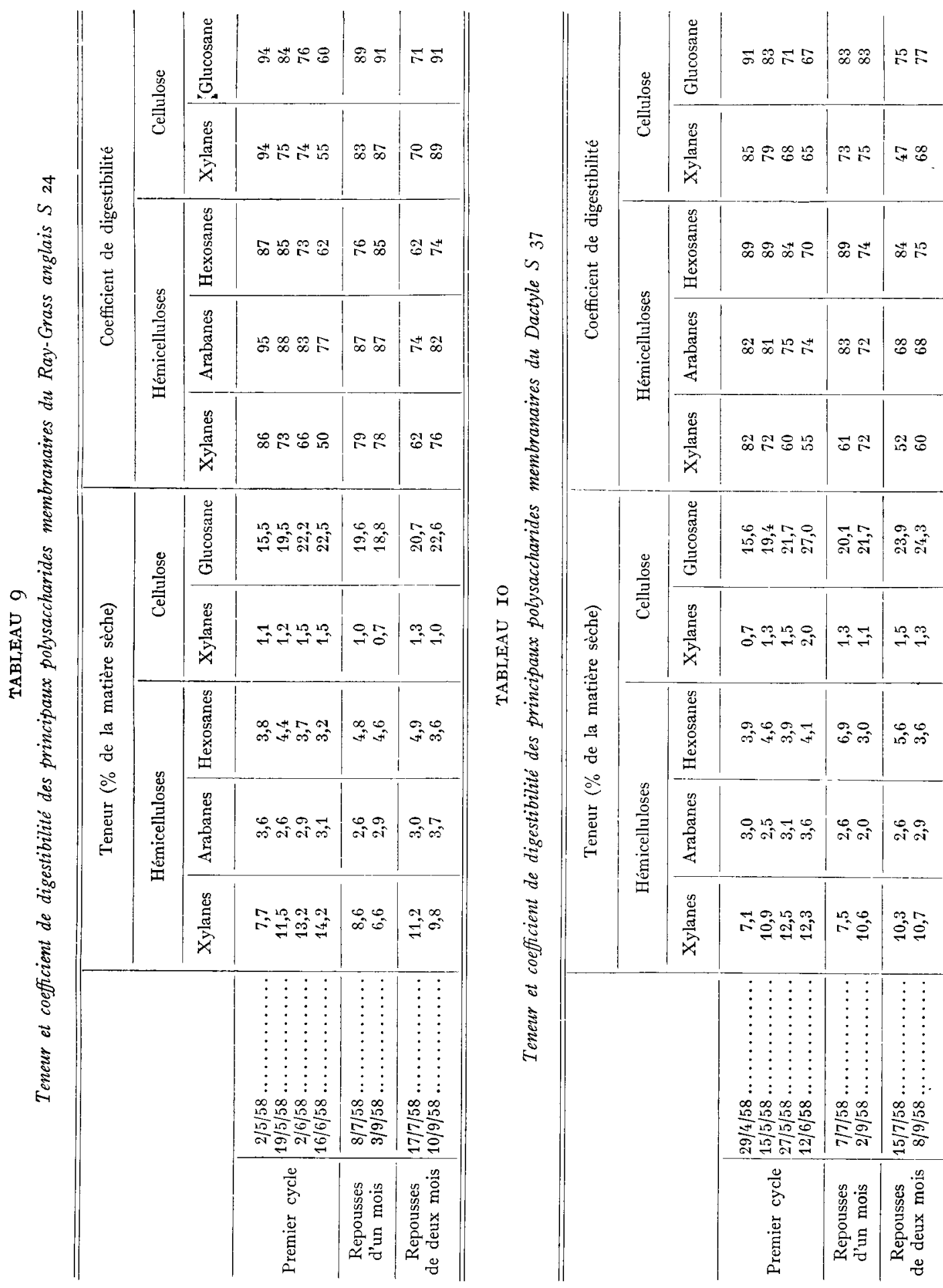
Les teneurs en arabanes et en hexosanes hydrolysables ont été faibles et relativement peu variables: respectivement $3,05 \mathrm{p}$. IOO $\pm 0,4 \mathrm{I}$ et $4, \mathrm{I} 2 \mathrm{p}$. IOO $\pm 0,63 \mathrm{chez}$ le ray-grass, et 2,79 p. IOO $\pm 0,48$ et 4,45 p. Ioo \pm I,25 chez le dactyle. Les xylanes ont été des constituants beaucoup plus importants et variables (en gros de $\delta$ à I6 p. Ioo de la matière sèche) ; en moyenne 88,5 p. Ioo ont été recouvrés dans la fraction hémicelluloses dont ils ont représenté de 50-55 p. Ioo au stade feuillu à 60-70 p. Ioo après épiaison.

La teneur en xylanes a varié en sens inverse de la proportion de limbes et, fait intéressant, elle a été généralement plus élevée chez le ray-grass que chez le dactyle. Le glucosane, ou cellulose vraie, a représenté en moyenne 94,5 p. Ioo de la fraction cellulose, et a donc varié comme cette dernière.

Ces divers polysaccharides ont eu une digestibilité nettement différente : en moyenne pour les 16 échantillons, $67,8 \mathrm{p}$. Ioo pour les xylanes des hémicelluloses, 74 , I p. Ioo pour les xylanes résiduels, $78,6 \mathrm{p}$. Ioo pour les hexosanes hydrolysables, 79,7 p. Ioo pour les arabanes et 80,3 p. Ioo pour la cellulose vraie. Les xylanes des hémicelluloses ont été significativement moins digestibles $(\mathrm{P}<0, \mathrm{oI})$ que tous les autres polysaccharides; de même, les xylanes résiduels ont toujours été moins digestibles que la cellulose vraie, et l'ensemble des pentosanes moins digestibles que l'ensemble des hexosanes. Au cours du ier cycle, la digestibilité de tous les polysaccharides a diminué chez les deux espèces, mais de façon beaucoup plus importante pour la cellulose vraie et les xylanes que pour les hexosanes hydrolysables et les arabanes.

Au stade de développement équivalent, les xylanes et les arabanes du raygrass ont été plus digestibles que ceux du dactyle $(\mathrm{P}<0,05)$ mais cela a été plutôt l'inverse pour les hexosanes hydrolysables (différence non significative).

\section{Lignine}

La teneur en lignine corrigée a présenté des valeurs minimum au début du premier cycle, de l'ordre de 2 à 2,5 p. Ioo chez le ray-grass $\mathrm{S} 24$ et de 3 à $3,5 \mathrm{p}$. roo chez le dactyle $\mathrm{S} 37$. Elle a augmenté de façon relativement rapide à partir de l'épiaison et plus lentement à partir d'une date qui doit correspondre approximativement au début de la floraison; à la fin du I $^{\text {er }}$ cycle elle a été de l'ordre de 6 à 6,5 p. Ioo chez le ray-grass et de 7 à 8 p. Ioo chez le dactyle. La teneur en lignine des repousses mensuelles a été beaucoup moins variable que celle des plantes du I er cycle; elle a eu tendance à diminuer avec l'avancement de la saison de végétation chez le ray-grass mais non chez le dactyle. La teneur des repousses âgées de deux mois a été nettement plus élevée que celle des repousses mensuelles, la différence s'amenuisant en automne.

A composition morphologique comparable les repousses ont contenu plus de lignine que les plantes du I ${ }^{\text {er }}$ cycle ; à la même date de prélèvement, le dactyle S 37 en a contenu plus que le ray-grass $S$ 24: la différence entre ces deux espèces a été en moyenne de $\mathbf{I}, \mathbf{I}$ point (pour 30 prélèvements), mais elle a eu tendance à diminuer à la fin du $\mathrm{I}^{\mathrm{er}}$ cycle.

Le coefficient de digestibilité de la lignine corrigée a été généralement compris entre - I5 et + $x_{5}$ p. Ioo; il a été en moyenne de 0,3 p. Ioo et de 0,2 p. Ioo respectivement pour l'ensemble des échantillons de ray-grass $S 24$ et de dactyle S 37 . I1 n'a pas présenté avec 1'âge au cours du I $^{\text {er }}$ cycle ni avec la saison dans le cas des 
repousses, de variations systématiques communes aux deux espèces et aux deux années étudiées. Chez le dactyle cependant, il a suivi au cours du rer cycle de croissance, une évolution " en cloche " avec des valeurs négatives au début du cycle, franchement positives aux environs de l'épiaison et plus faibles à la fin du cycle. Par ailleurs, il a varié en sens inverse de la teneur en lignine dans le cas des repousses, chez le ray-grass plus particulièrement.

TABLEAU II

Relations entre la lignocellulose et la cellulose brute WEENDE et la somme cellulose plus lignine corrigée

\begin{tabular}{|c|c|c|c|}
\hline & $\begin{array}{l}\text { Nombre } \\
\text { d'échan- } \\
\text { tillons }\end{array}$ & Lignocellulose & Cellulose brute WEEnde \\
\hline $\begin{array}{c}\text { Ray-Grass } S 24 \\
1^{\mathrm{er}} \text { cycle }\end{array}$ & 17 & $\begin{array}{l}r=0,988 \\
y=0,93 x+6,00( \pm 0,20)\end{array}$ & $\begin{array}{l}r=0,993 \\
y=1,05 x-0,14( \pm 0,56)\end{array}$ \\
\hline Repousses & 13 & $\begin{array}{l}r=0,902 \\
y=0,87 x+8,05(\text { ㄴ } 1,07)\end{array}$ & $\begin{array}{l}r=0,951 \\
y=1,01 x+0,98( \pm 0,85)\end{array}$ \\
\hline Ensemble & 30 & $\begin{array}{l}r=0,984 \\
y=0,87 x+7,60(10,62)\end{array}$ & $\begin{aligned} r & =0,986 \\
y & =0,999 x+1,25(\text { L } 0,65)\end{aligned}$ \\
\hline $\begin{array}{c}\text { Daclyle } S 37 \\
1^{\text {er }} \text { cycle }\end{array}$ & 19 & $\begin{array}{l}r=0,992 \\
y=0,92 x+6,70( \pm 0,66)\end{array}$ & $\begin{array}{l}r=0,989 \\
y=1,02 x+0,16( \pm 0,86)\end{array}$ \\
\hline Repousses & 13 & $\begin{array}{l}r=0,95^{\prime} \\
y=0,8 \pm x+9,75(\therefore 0,93)\end{array}$ & $\begin{array}{l}r=0,987 \\
y=1,03 x+0,06( \pm 0,58)\end{array}$ \\
\hline Ensemble & 32 & $\begin{array}{l}r=0,980 \\
y=0,88 x+8,33(! \quad 0,88)\end{array}$ & $\begin{array}{l}r=0,989 \\
y=1,01 x+0,44( \pm 0,75)\end{array}$ \\
\hline Ensemble & 62 & $\begin{array}{l}r=0,996 \\
y=0,95 x+6,11(\text { 上 } 0,38)\end{array}$ & $\begin{array}{l}r=0,986 \\
y=1,005 x+0,85( \pm 0,78)\end{array}$ \\
\hline
\end{tabular}

Le coefficient de digestibilité de la lignine corrigée a été systématiquement plus faible que celui de la lignine brute, dont les valeurs moyennes ont été respectivement de I3,9 p. Ioo et de II,9 p. Ioo pour le ray-grass et pour le dactyle, et qui n'a présenté que deux valeurs négatives pour les 62 échantillons.

\section{Lignocellulose et cellulose brute WEENDE}

Les teneurs en lignocellulose et en cellulose brute WEENDE, ont toutes deux varié comme la somme cellulose + lignine avec laquelle elles ont présenté une liaison linéaire extrêmement étroite, très semblable pour le ray-grass et le dactyle (tabl. II) Le coefficient de régression a été plus faible pour la lignocellulose que pour la cellulose brute, parce que les matières azotées de la lignocellulose (exprimées en p. roo du fourrage) diminuent quand la teneur en azote du fourrage diminue, et par suite 
quand la teneur en cellulose et lignine augmente. La lignocellulose et la cellulose brute WEENDE sont detux critères très satisfaisants de la somme cellulose + lignine corrigée ; la lignocellulose est un meilleur critère que la cellulose brute pour les plantes du I $^{\text {er }}$ cycle, surtout après l'épiaison, mais elle est moins satisfaisante pour les plantes riches en matières azotées comme les repousses feuillues.

Les coefficients de digestibilité de la lignocellulose et de la cellulose brute WEENDE ont varié dans des limites très grandes (de 36, I à 83,6 p. Ioo et de 47,4 à 90,7 p. Ioo respectivement), dans le même sens que celui de la cellulose. Ils ont présenté avec ce dernier une liaison très étroite (tabl. I2) ; les coefficients de régression ont été plus élevés pour la lignocellulose que pour la cellulose brute au ${ }^{\text {er }}$ cycle, mais plus faibles dans le cas des repousses.

\section{Fraction indéterminée}

La fraction indéterminée a été obtenue en soustrayant de la tenetır en matière sèche la somme de tous les constituants déterminés : cendres + matières azotées + glucides solubles + extrait au dégraissage + hémicelluloses + cellulose + lignine corrigée.

\section{TABLEAU I2}

Relations entre la digestibilité de la lignocellulose, de la cellulose brute WEENDE et la digestibilité de la cellulose (x)

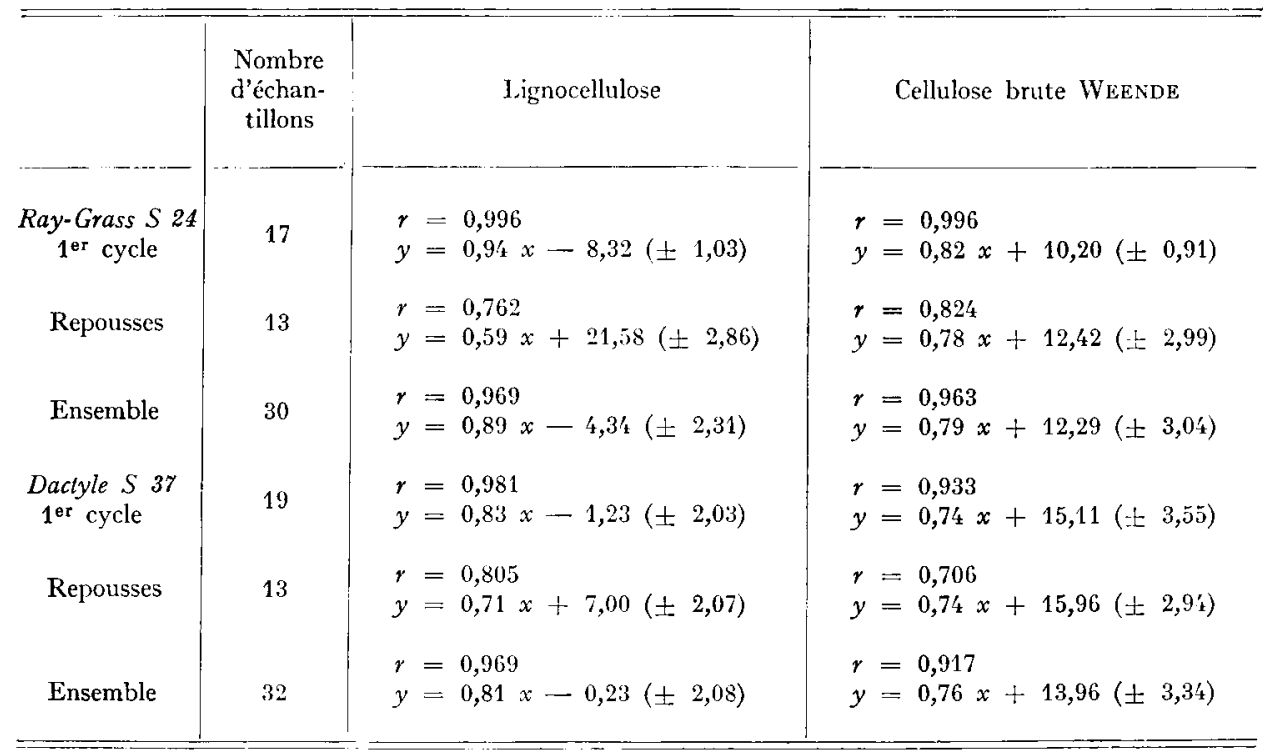

Elle a été relativement peu variable et a présenté des valeurs moyennes de 14,8 et $\mathrm{I} 6,7 \mathrm{p}$. Ioo respectivement, pour les plantes du $\mathrm{I}^{\mathrm{er}}$ cycle et pour les repousses du ray-grass, et de 15,9 et $\mathrm{I} 6,4 \mathrm{p}$. Ioo pour les plantes correspondantes de dactyle. La digestibilité de cette fraction indéterminée a varié grossièrement dans le même sens que celle de la matière organique, et a été en moyenne du même ordre. 
QUANTITÉS DIGESTIBIES ET INDIGESTIBIES DE CHAQUE CONSTITUANT

Pour interpréter les variations de la teneur et de la composition de la matière organique digestible et de la matière organique indigestible (ballast), nous avons calculé les teneurs digestibles et indigestibles de chaque constituant en pourcentage
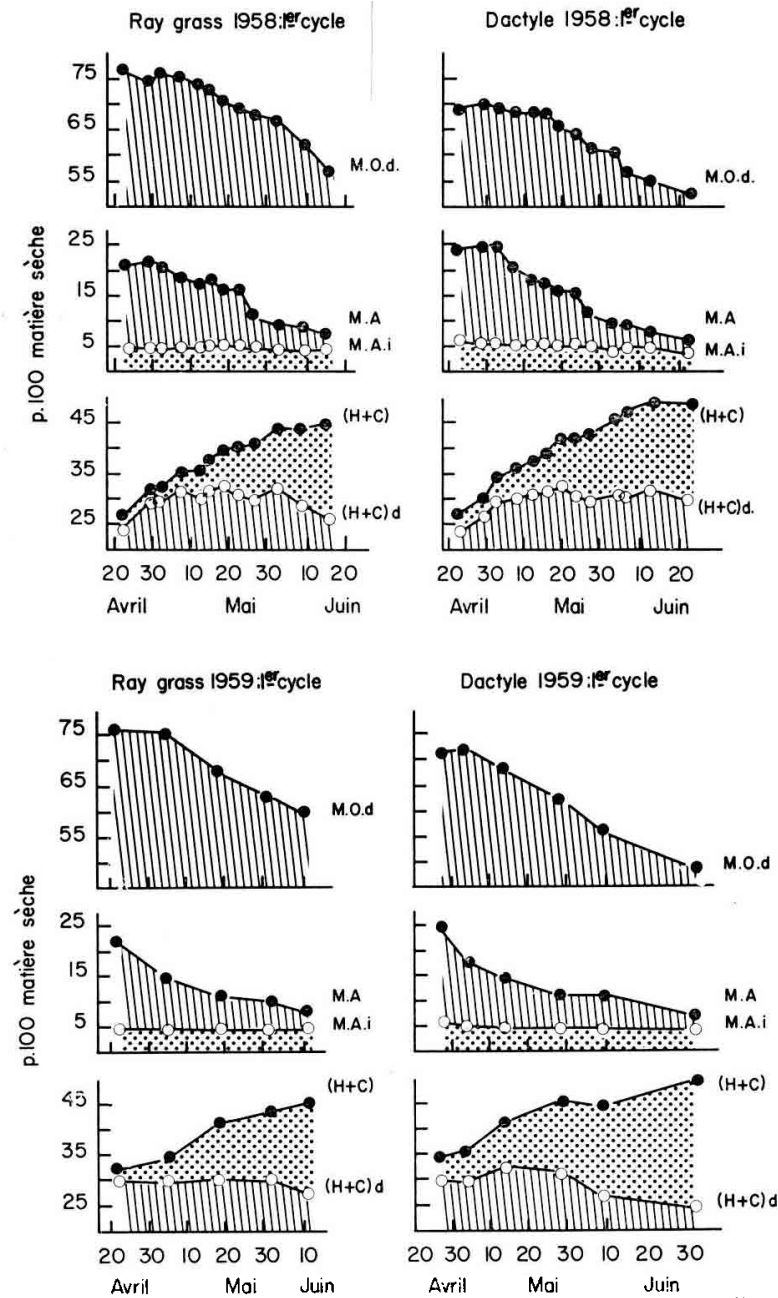

FIG. 7- Evolution au cours du premier cycle de croissance des teneurs en matière organique digestible (M.O.d.), en matières azotées digestibles et indigestibles (M. A. i.), en polysaccharides membranaires (hémicelluloses + cellulose $)$ digestibles $(H+C . d$. $)$ et indigestibles

de la matière sèche du fourrage (exemple : quantité de cellulose digestible $=$ teneur en cellulose $\times$ coefficient de digestibilité de cette cellulose). Les figures 7 et 8 présentent les résultats obtenus pour la matière organique, les matières azotées et la somme 
hémicelluloses + cellulose ; elles ne montrent pas les glucides solubles puisqu'ils sont entièrement digestibles, ni la lignine puisqu'on peut la considérer pratiquement comme entièrement indigestible.
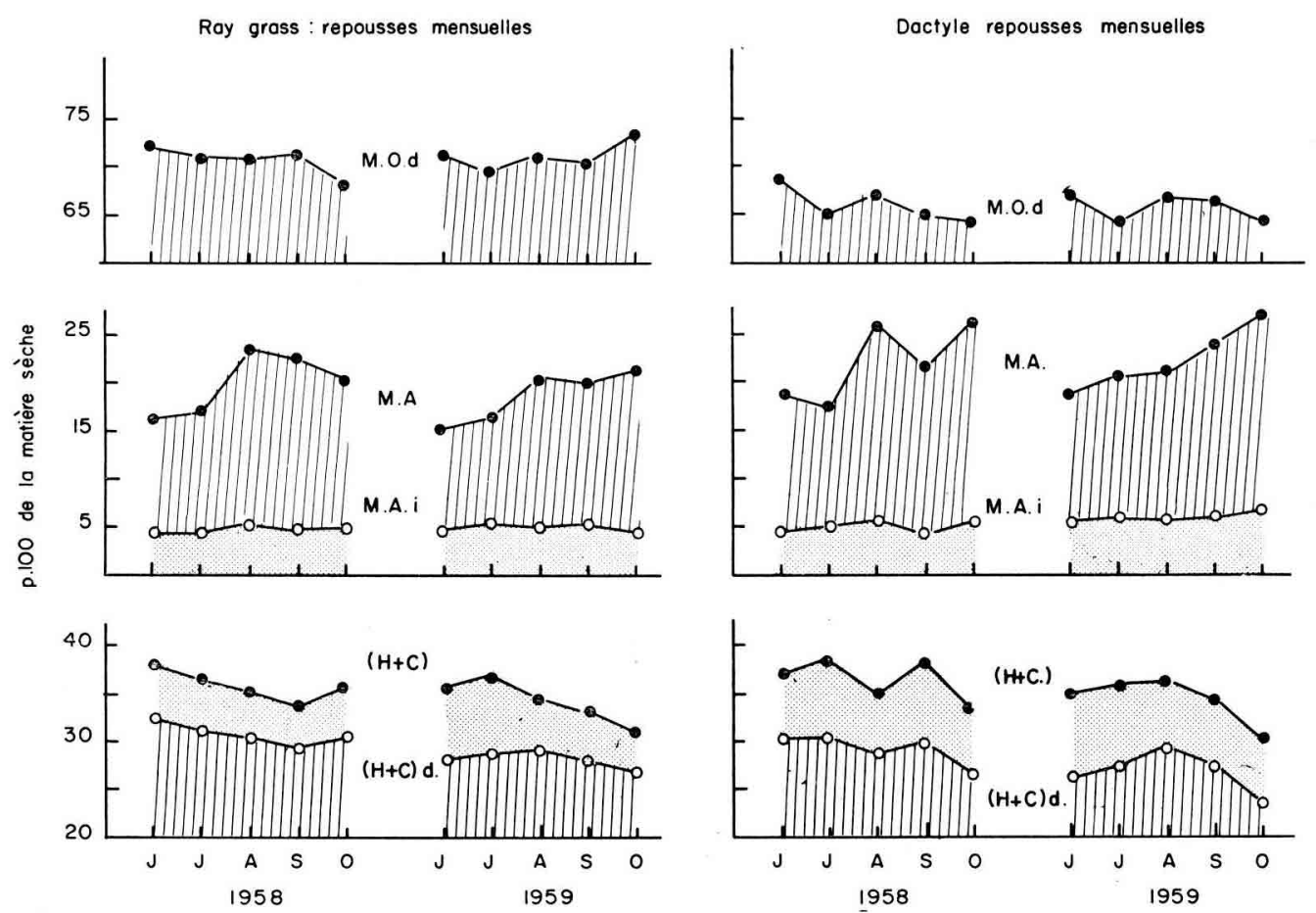

FIG. 8. - Variations dans les repousses mensuelles des teneurs en matière organique digestible $(M .0$. d.), en matières azotées digesibles et indigestibles $(M . A . i$.$) , en polysaccharides membranaires (hémicelluloses +$ cellulose) digestibles $(H+C . d$.) et indigestible

\section{Constituants cytoplasmiques}

La teneur en matières azotées apparemment non digestibles a été presque constante, comme on pouvait s'y attendre d'ailleurs; elle a été en moyenne de 4,52 p. IOO $\pm 0,34$ pour l'ensemble des ray-grass et de 5,02 p. IOO $\pm 0,68$ pour 1'ensemble des dactyles, la différence entre ces deux espèces étant significative. Elle a eu cependant tendance à varier dans le même sens que la teneur en matières azotées mais de façon très limitée. La teneur en matières azotées digestibles peut donc être estimée de façon très satisfaisante en soustrayant de la teneur en matières azotées les constantes précédentes.

La teneur en constituants " lipidiques" (extrait au dégraissage) apparemment digestibles, a diminué plus ou moins régulièrement au cours du I ${ }^{\text {er }}$ cycle de croissance, passant de plus de $5 \mathrm{p}$. Ioo à moins de $2 \mathrm{p}$. Ioo ; elle a fluctué dans les repousses et a été généralement comprise entre 2,5 et $4 \mathrm{p}$. Ioo. La teneur en constituants 
" lipidiques " apparemment non digestibles a varié dans le même sens que la teneur totale, et a été relativement plus élevée dans les repousses d'automne que dans les plantes du I $^{\text {er }}$ cycle.

\section{Constituants membranaires}

Exception faite d'une valeur faible pour le premier échantillon prélevé en $195^{8}$ (plantes exclusivement fetillues), les teneurs en hémicelluloses digestibles et en cellulose digestible ont été approximativement constantes pendant la majeure partie du I er cycle de croissance : elles ont présenté respectivement des valeurs de l'ordre de I3-I4 p. Ioo et I6-I8 p. Ioo, aussi bien pour le ray-grass que pour le dactyle d'une part, en I959 qu'en I958 d'autre part. Il y a donc eu pendant cette période une compensation presque rigoureuse entre l'augmentation de la teneur du constituant et la diminution de son coefficient de digestibilité ; en d'autres termes tout s'est passé comme si l'accroissement des teneurs en hémicelluloses et cellulose était entièrement indigestible (fig. 7 ).

A partir du début juin (début de la floraison), lorsque la proportion de limbes est devenue inférieure à 20-25 p. IOo, les teneurs en hémicelluloses digestibles et en cellulose digestible ont eu cependant tendance à diminuer, parce que les teneurs des constituants augmentaient peu alors que leur digestibilité diminuait rapidement. Corrélativement, les teneurs en hémicelluloses et en cellulose non digestibles augmentaient plus rapidement qu'auparavant.

A proportion de limbes égale, les repousses ont contenu pratiquement la même proportion d'hémicelluloses digestibles mais une proportion de cellulose digestible sensiblement plus élevée que les plantes du ${ }^{e r}$ cycle, parce qu'elles contenaient plus de cellulose totale. De même, à âge comparable, les repousses de raygrass ont eu des teneurs légèrement plus élevées en hémicelluloses digestibles $(\mathrm{P}<0,0 \mathrm{I})$ et en cellulose digestible (différence non significative) que les repousses de dactyle, alors qu'il n'y avait pas de différence entre les deux espèces, à cet égard, pour les plantes du I I $^{\text {er }}$ cycle.

On peut dire cependant, que la majeure partie des plantes de ray-grass et de dactyle étudiées ont contenu de l'ordre de $30 \mathrm{p}$. Ioo de constituants membranaires digestibles, à l'exception des plantes exclusivement feuillues du tout début du $\mathrm{I}^{\mathrm{er}}$ cycle et des repousses d'octobre-novembre, ainsi que des plantes à partir de la pleine floraison. Les teneurs en polysaccharides digestibles ont été également moins variables que les teneurs brutes, notamment au cours du I ${ }^{\text {er }}$ cycle de croissance, mais ont présenté certaines différences systématiques entre les deux espèces : le ray-grass a contenu plus de xylanes digestibles que le dactyle (7,I p. Ioo au lieu de 6,5 p. IOo), plus d'arabanes digestibles mais moins d'hexosanes hydrolysables digestibles.

\section{COMPOSITION DE LA MATIÈRE ORGANIQUE DIGESTIBLE}

Les variations précédentes des quantités digestibles des différents constituants, n'ont pas seulement déterminé des variations de la teneur de la plante en matière organique digestible ; elles ont également entraîné des variations importantes de la composition de cette dernière qu'illustrent les figures 9 et ro.

Au cours du $\mathrm{I}^{\mathrm{er}}$ cycle de croissance, la proportion des matières azotées diges- 
tibles dans la matière organique digestible a diminué rapidement, alors que celle des hémicellulose et de la cellulose digestible augmentait. A partir de l'épiaison, ces deux fractions ont représenté approximativement $45 \mathrm{p}$. Ioo de la matière organique

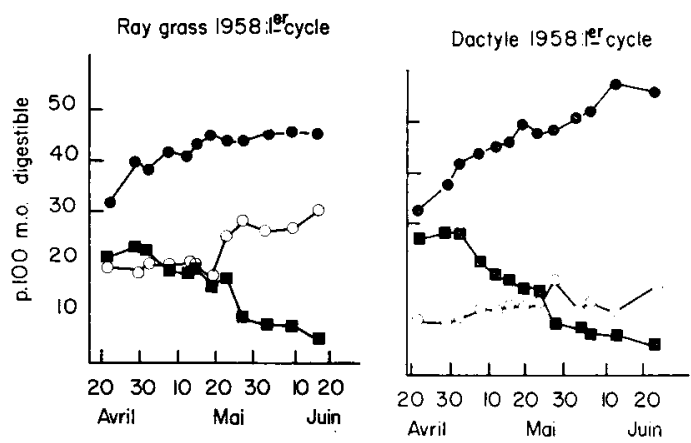

Ray grass $1959{ }^{\text {er }}$ cycle

Dactyle $1959: 1^{\text {er }}$ cycle

FIG. 9. - Evolution au cours du premier cycle de croissance de la composition de la matière organique digestible

- (hémicelluloses - cellulose) digestibles

- matières azotées digestibles

o glucides solubles

Ray grass: repousses mensuelles

Doctyle : repousses mensuelles
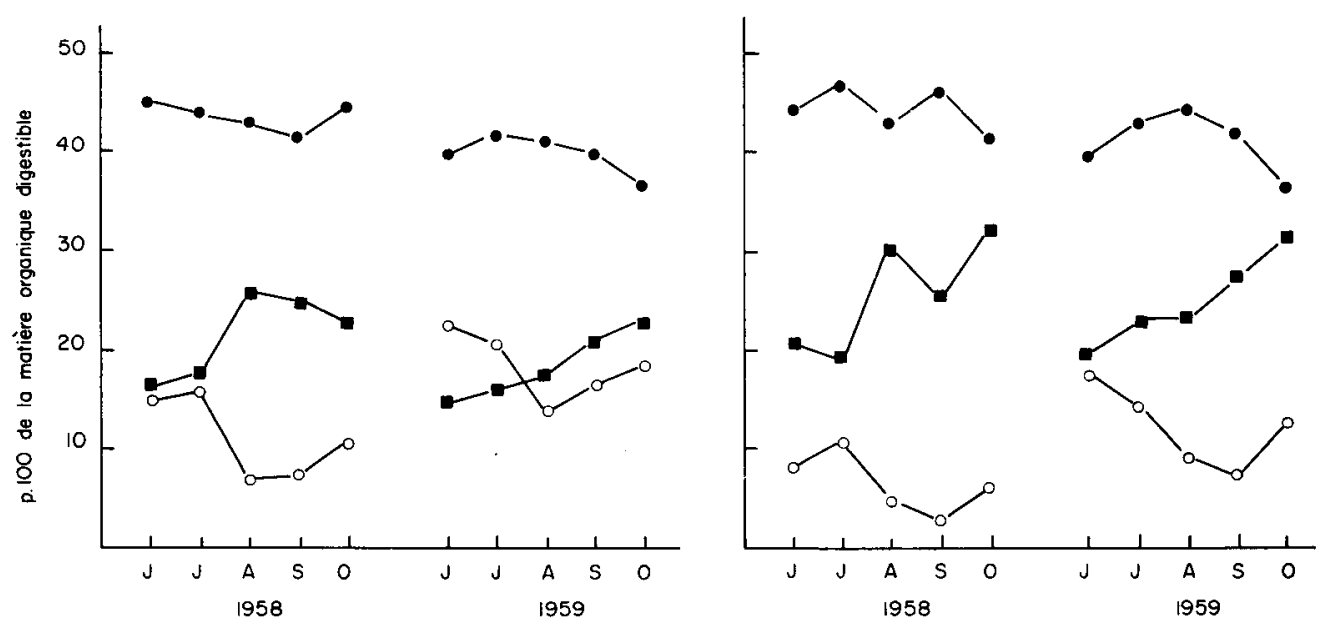

FIG. Io. - Variations dans les repousses mensuelles de la composition de la matière organique digestible

- (hémicelluloses $\therefore$ cellulose) digestibles

- matières azotées digestibles

0 glucides solubles

digestible du ray-grass et 50-55 p. Ioo de celle du dactyle. La proportion des glucides solubles a eu tendance à augmenter de façon plus ou moins irrégulière, et la proportion de l'indéterminé digestible a diminué. 
Ce sont les matières azotées digestibles et les glucides solubles qui ont été les constituants les plus variables de la matière organique digestible des repousses (fig. Io). La proportion de matières azotées digestibles a augmenté de façon plus ou moins régulière avec l'avancement de la saison de végétation ; celle des glucides solubles a été minimum en août-septembre et beaucoup plus élevée en I959 qu'en r958. Quant à la proportion des polysaccharides membranaires digestibles, elle a été beaucoup moins variable qu'au $\mathrm{I}^{\mathrm{er}}$ cycle ; elle a été généralement comprise entre 40 et 45 p. Ioo et sensiblement plus faible en I959 qu'en I958.

A stade de végétation comparable, la matière organique digestible du ray-grass a contenu beaucoup plus de glucides solubles que celle du dactyle, mais moins de membranes digestibles et de matières azotées digestibles. Au total, les glucides solubles ont été les constituants les plus variables de la matière organique digestible dont ils ont représenté de moins de $3 \mathrm{p}$. Ioo à plus de $30 \mathrm{p}$. Ioo.

\section{MATIÈRE ORGANIQUE INDIGESTIBLE}

Ia teneur en matière organique indigestible, ou ballast, a présenté des variations plus importantes en valeur absolue et en valeur relative, que la teneur en matière organique digestible ; en effet, la teneur en matière organique varie en sens inverse de la digestibilité, donc dans le même sens que l'indigestibilité, surtout au cours du i er cycle de croissance.

La teneur en ballast du fourrage dépend avant tout de la teneur en lignine et polysaccharides membranaires non digestibles ; en effet, les matières azotées apparemment non digestibles demeurent pratiquement constantes (fig. 7 et 8) et les " matières grasses " non digestibles ont tendance à diminuer quand le ballast augmente. Le ballast contient également la fraction non digestible des constituants non déterminés qui augmente en même temps que l'indigestible membranaire.

La teneur en ballast a présenté des relations extrêmement étroites avec les teneurs en lignine, en hémicelluloses non digestibles, en cellulose non digestible en lignocellulose non digestible et en cellulose brute non digestible (tab1. r3)., La lignine est systématiquement le moins bon de ces critères du ballast ; la lignocellulose non digestible est généralement le meilleur et permet d'estimer le ballast avec une erreur très faible, même lorsqu'on considère l'ensemble des échantillons.

\section{DISCUSSION}

\section{Variations de la digestibilité de la matière organique}

Les résultats précédents nous permettent maintenant d'expliquer les variations de la teneur en matière organique digestible $(D)$ en relation avec le stade de croissance, la saison et l'espèce. Des deux composantes de $\mathrm{D}$, la teneur en matière organique est la moins variable mais elle présente, tout de même, certaines différences non négligeables avec la proportion de limbes et les conditions saisonnières et cli- 


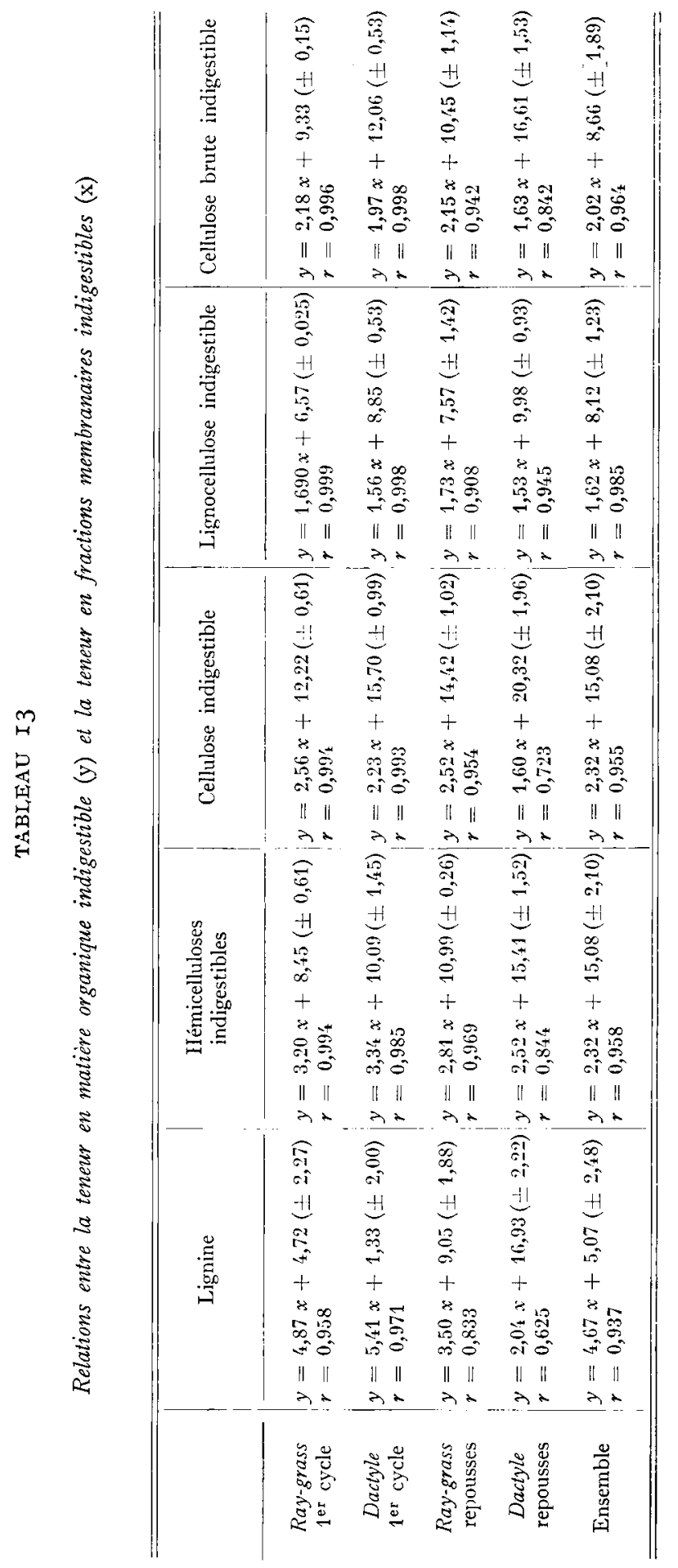


matiques : par exemple, le fait qu'elle augmente au cours du premier cycle ralentit sensiblement la diminution de $\mathrm{D}$. La deuxième composante, à savoir le coefficient de digestibilité de la matière organique, présente des variations beaucoup plus importantes (de 50,6 à 85, I p. roo pour les fourrages étudiés) selon les proportions respectives et la digestibilité des principaux constituants organiques.

Ces derniers ont tous des teneurs très variables, avant tout en fonction de la composition morphologique de la plante, mais ils se comportent différemment du point de vue de leur digestibilité. On peut ainsi les répartir en quatre catégories :

I) les glucides solubles qui sont entièrement digestibles ;
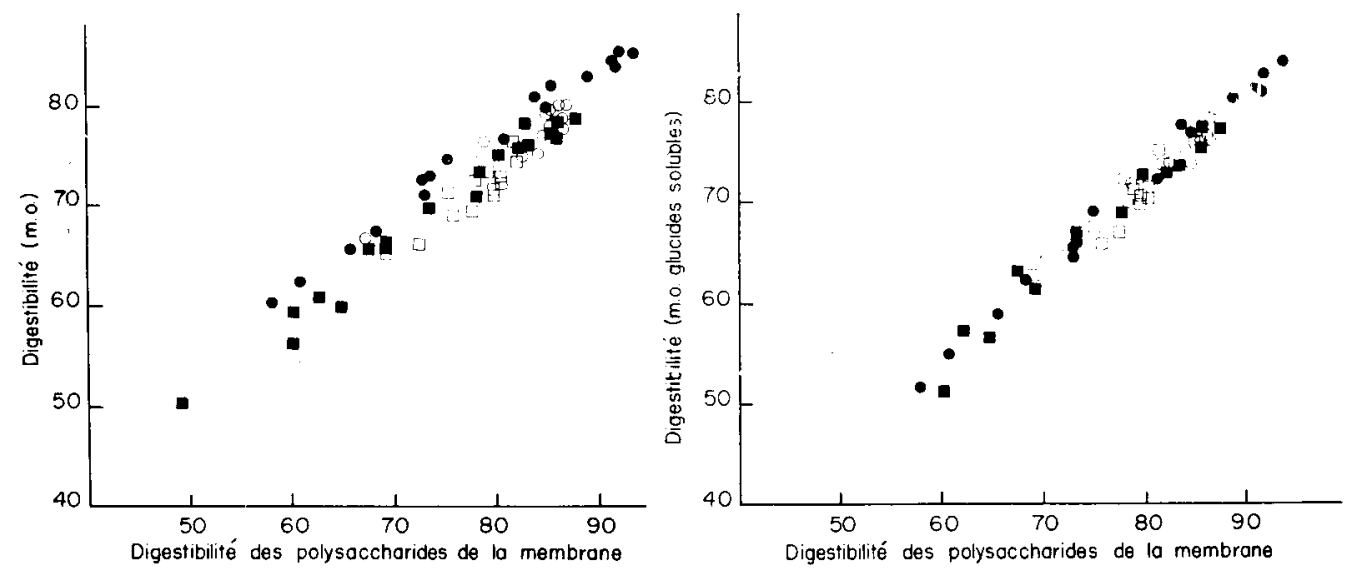

FIg. II. - Relations entre la digesibilité de la matière organique (1 Ia) ou la digestibilité de la matière organique moins glucides solubles (I $\mathrm{ib}$ ), et la digestibilité des polysaccharides membranaires (hémicelluloses + cellulose)

- Ray-grass S $24: 1^{\text {tr cycle }}$
ORay-grass S $24:$ repousses

- Dactyle S 37 ; $1^{\text {er }}$ cycle

D Dactylé S 37 : repousses

2) les matières azotées et les constituants lipidiques dont la digestibilité réelle peut être considérée comme constante, tout au moins pour une espèce donnée. C'est là un fait bien connu pour les matières azotées : on peut en voir une 'nouvelle preuve dans le fait que la teneur en matières azotées non digestibles a été pratiquement constante pour les échantillons de chacune c̉e nos deux espèces, les valeurs observées étant en excellent accord avec celles obtentes notamment par HoLTER et REID (I959) et par DEMARquILLy et JARRIGE (I964). Il est probable que la digestibilité réelle des constituants lipidiques a été grossièrement constante puisque la digestibilité apparente de la fraction extraite par le mélange alcool-benzène n'a pas présenté d'évolution très nette.

3) les polysaccharides membranaires, hémicelluloses et cellulose, dont la digestibilité varie dans des limites extrêmement larges, presque du simple au double, dans les fourrages étudiés ;

4) la lignine qu'on peut considérer comme étant pratiquement indigestible malgré les fluctations observées (cf. discussion de JOURNÉT et JARRIGE, I 962).

Il n'est pas étonnant dans ces conditions que la digestibilité de la matière 
organique présente une liaison très étroite avec la digestibilité des polysaccharides membranaires, de la lignocellulose ou de la cellulose brute (tab1. I4) (fig. II $a$ ).

La liaison devient encore plus étroite entre la digestibilité de la matière organique sans les glucides solubles, lesquels sont entièrement digestibles, et la digestibilité des polysaccharides membranaires représentés par la somme hémicelluloses + cellulose (fig. II $b$ ) :

$$
y=0,865 x+2,02 \quad( \pm \text { I,II }) \quad r=0,99 I
$$

TABLEAU I4

Relations entre le coefficient de digestibilité de la matière organique et les coefficients de digestibilité des constituants de la membrane pour l'ensemble des 62 échantillons

\begin{tabular}{|c|c|}
\hline Variable $x$ & Digestibilité de la matière organique $(y)$ \\
\hline Digestibilité des hémicelluloses $\left(x_{1}\right)$ & $\begin{array}{l}y=0,814 x_{1}+12,10( \pm 1,48) \\
\gamma=0,979\end{array}$ \\
\hline Digestibilité de la cellulose $\left(x_{2}\right)$ & $\begin{array}{l}y=0,668 x_{2}+18,87( \pm 2,18) \\
r=0,954\end{array}$ \\
\hline $\begin{array}{c}\text { Digestibilité de la somme }\left(x_{3}\right) \\
\text { hémicelluloses }+ \text { cellulose }\end{array}$ & $\begin{array}{l}y=0,738 x_{3}+15,31( \pm 1,98) \\
r=0,962\end{array}$ \\
\hline Digestibilité de la lignocellulose $\left(x_{4}\right)$ & $\begin{array}{l}y=0,741 x_{4}+23,70( \pm 2,01) \\
r=0,961\end{array}$ \\
\hline Digestibilité de la cellulose brute WEENDE $\left(x_{5}\right)$ & $\begin{array}{l}y=0,776 x_{5}+14,04( \pm 2,86) \\
r=0,919\end{array}$ \\
\hline
\end{tabular}

Plusieurs auteurs ont déjà constaté une telle liaison entre la digestibilité du fourrage et la digestibilité de la cellulose estimée soit par la méthode de WEENDE, soit par la méthode de Crampton et MaynarD. Enn définitive la digestibilité de la matière organique des plantes étudiées dépend donc essentiellement de la digestibilité des membranes, mais présente cependant certaines modifications dues aux variations de la teneur en glucides solubles :

I) Elle demeure très élevée jusqu'à l'épiaison bien que la proportion de limbes et de matières azotées diminue et que la proportion de membranes augmente, parce que les polysaccharides membranaires sont très digestibles, presque aussi digestibles que les constituants cytoplasmiques qu'ils remplacent. Elle diminue ensuite parce que la digestibilité des membranes diminue en même temps qu'augmente la teneur de celles-ci ; elle continue à diminuer encore à la fin du premier cycle, bien que la composition de la plante change peu, parce que la digestibilité des membranes continue à diminuer.

2) A composition morphologique égale, les repousses sont moins digestibles que les plantes du premier cycle, parce qu'elles ont des membranes moins digestibles (fig. 5 et 6 ) et contiennent généralement moins de glucides solubles, surtout à 
la mi-été. Les repousses mensuelles de I959, année sèche, sont souvent moins digestibles que les repousses correspondantes de 1958, année humide, parce que leurs membranes sont nettement moins digestibles; la différence est cependant atténuée du fait qu'elles sont beaucoup plus riches en fructosanes et glucides solubles.

3) De même, à âge ou à composition morphologique comparable, le ray-grass S 24 est toujours plus digestible que le dactyle S 37 pour deux raisons (fig. I) : parce qu'il a des membranes plus digestibles et, parce qu'il contient plus de fructosanes et de glucides solubles.

\section{Variations de la digestibilité des polysaccharides membranaires}

Il s'agit maintenant d'interpréter les variations de la digestibilité des polysaccharides membranaires. On doit d'abord en chercher l'explication dans les variations de 1'une ou de plusieurs des trois caractéristiques des membranes : (I) leur composition caractérisée plus particulièrement par leur teneur en lignine ; (2) leur teneur dans le fourrage et (3) la structure de leurs polysaccharides. Il ne faut cependant pas négliger l'interférence possible de facteurs indépendants des membranes, tels que la concentration de certains constituants cytoplasmiques et l'activité de la population bactérienne du rumen.

I) On attribue généralement un rôle prépondérant au degré de lignification en s'appuyant sur diverses données : relations hautement négatives entre la digestibilité et la teneur en lignine (CRAMpTON et MAYNARD, I938), présence des tissus lignifiés dans les fèces (Drapala et al., I947; REGAL, I960), observations microscopiques des plantes en voie de digestion (BAKER, I947), modifications de la digestibilité de la cellulose à la suite de la délignification (FERGUSON, I942) ou du broyage intense de la plante (DEHORITy et Johnson, I96I). Il semble bien en être ainsi pour nos échantillons: la digestibilité des hémicelltuloses, de la cellulose ou de leur somme présente une liaison très étroite avec la teneur en lignine (tabl. I5). Corrélativement la teneur en polysaccharides membranaires indigestibles augmente avec la teneur en lignine suivant une loi très comparable pour les plantes des différents cycles de croissance d'une part, pour les ray-grass et les dactyles d'autre part (tabl. I5- fig. I2) ; lorsque la teneur en lignine augmente d'un point, la teneur en polysaccharides membranaires non digestibles augmente de trois à quatre points.

Il est à noter que les différentes liaisons sont plus étroites (d'après l'écart type) pour les hémicelluloses que pour la cellulose ou la somme hémicelluloses + cellulose ; elles apparaissent par ailleurs plus lâches lorsque la lignine est exprimée en pourcentage des membranes parce qu'elles sont alors en réalité curvilinéaires.

La digestibilité extrêmement élevée des polysaccharides membranaires au début du premier cycle de croissance, qui se maintient presque jusqu'à l'épiaison, peut être attribuée à la très faible lignification : la lignine ne représente alors que de 5 à 8 p. roo des membranes du ray-grass $\$ 24$ et de 8 à Io p. Ioo de celles du dactyle. Pendant cette période, les membranes des gaines et des très jeunes tiges sont aussi peu lignifiées que celles des limbes (JARRIGE, I963) ; c'est pourquoi les gaines sont aussi digestibles que les limbes (d'autant plus qu'elles sont plus riches en glucides solubles) et que les très jeunes tiges le sont même parfois plus (TII,L,EY, Ig6I ; PRITCHARD et $a l$., I963). 
Des environs de l'épiaison à ceux de la floraison, la teneur en membranes de la plante augmente rapidement d'abord parce que la proportion de tiges augmente, de même que celle des inflorescences et, ensuite, parce que la teneur en membranes

TABLEAU I5

Relations entre le coefficient de digestibilité (y) ou la quantité indigestible (z) des polysaccharides membranaires et la teneur de ces polysaccharides ou la teneur en lignine

\begin{tabular}{|c|c|c|c|}
\hline & & Coefficient de digestibilité $(y)$ & Quantité indigestible (z) \\
\hline 1. Hémicelluloses & $\begin{array}{l}x_{1} \text { hémicelluloses } \\
(\% \text { de la M. S.) } \\
x_{2} \text { lignine } \\
\text { (\% de la Y. S.) } \\
x_{3} \text { lignine } \\
\text { (\% des membranes) }\end{array}$ & 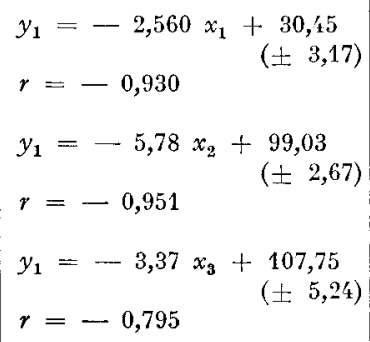 & 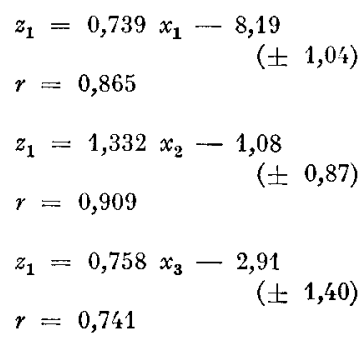 \\
\hline 2. Cellulose & $\begin{array}{l}x_{4} \text { cellulose } \\
(\% \text { de la M. S.) } \\
x_{2} \text { lignine } \\
(\% \text { de la M. S.) } \\
x_{3} \text { lignine } \\
\text { (\% des membranes) }\end{array}$ & 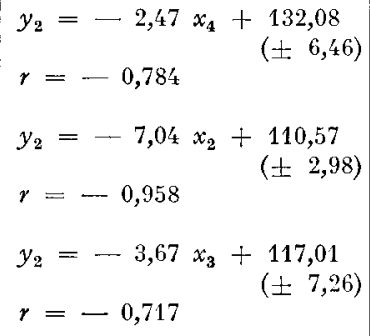 & $\begin{array}{l}z_{2}=0,750 x_{4}-11,32 \\
r=0,851 \\
z_{2}=1,870 x_{2}-3,69 \\
r=0,912 \quad( \pm 1,53) \\
z_{2}=1,036 x_{3}-5,97 \\
r=0,723 \quad( \pm 2,01)\end{array}$ \\
\hline $\begin{array}{l}\text { 3. Hémicelluloses } \\
+\quad \text { cellulose }\end{array}$ & $\begin{array}{l}x_{5} \text { hémicelluloses }+ \\
\text { cellulose ( } \% \text { de la } \\
\text { M. S.) } \\
x_{2} \text { lignine } \\
\text { (\% de la M. S.) } \\
x_{3} \text { lignine } \\
\text { (\% des membranes) }\end{array}$ & $\begin{array}{l}y_{3}=-0,688 x_{5}+106,36 \\
r=-0,683 \quad( \pm 6,94) \\
y_{3}=-5,95 x_{2}+103,20 \\
r=-0,890 \quad( \pm 4,33) \\
y_{3}=-3,49 x_{3}+112,43 \\
r=-0,749 \quad( \pm 6,29)\end{array}$ & $\begin{array}{l}z_{3}=0,375 x_{5}-6,66 \\
r=0,709 \\
z_{3}=3,026 x_{2}-4,03 \\
r=0,865 \quad( \pm 2,50) \\
z_{3}=1,66 x_{3}-7,56 \\
r=0,681 \quad( \pm 3,64)\end{array}$ \\
\hline
\end{tabular}

de chacun des organes augmente. La digestibilité des polysaccharides membranaires, plus spécialement celle de la cellulose et des xylanes, diminue de façon presque rigoureusement inverse au point que la quantité digestible de ces polysaccharides demeure sensiblement constante, ce qui est en accord avec les premières observations de TILLEY et al., (Ig60). Cette diminution peut être due en majeure partie à l'accroissement de la teneur en lignine des membranes, laquelle augmente jusqu'à 


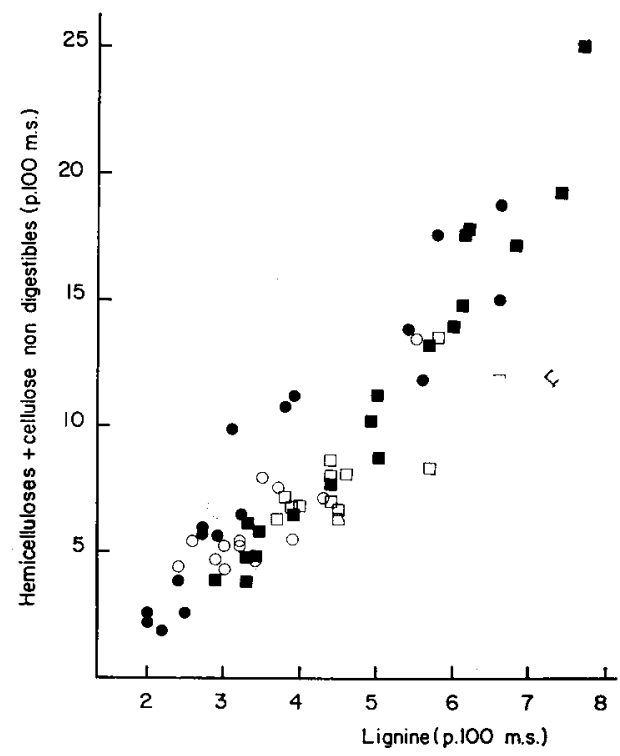

FIG. I2. - Relations entre la teneur en polysaccharides membranaires (hémicelluloses + cellulose) non digestibles et la teneur en lignine

- Ray-grass S $24: 1^{\text {or }}$ cycle

oRay-grass S 24 : repousses

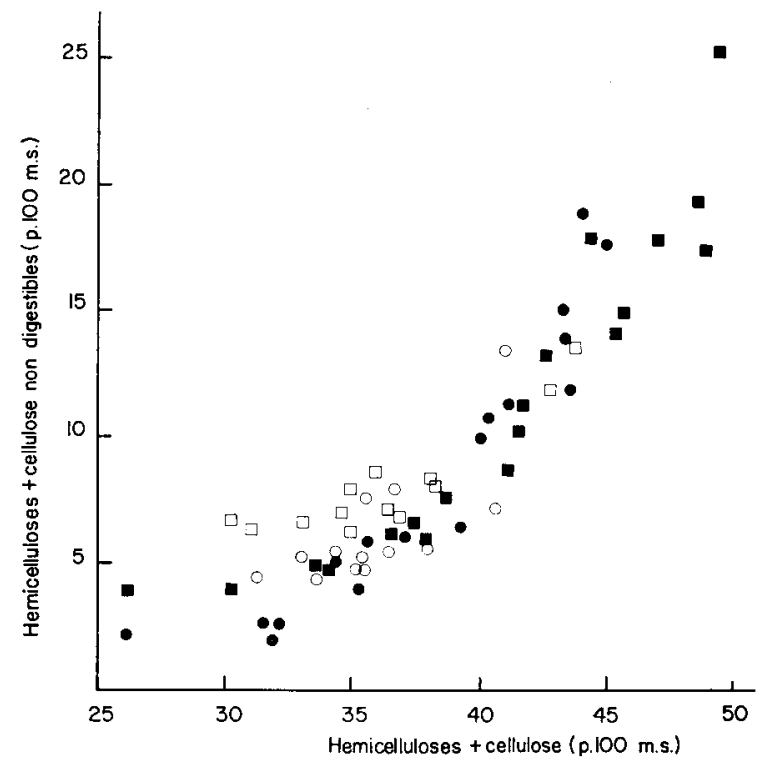

- Dactyle S 37 : 1er cycle

$\square$ Dactyle S 37 : repousses

FIG. I3. - Relations entre la teneur en polysaccharides membranaires (hémicelluloses + cellulose) non digestibles et la teneur en polysaccharides membranaires.

- Ray-grass S $24: 1^{\text {or }}$ cycle ORay-grass S 24 : repousses 
I2 p. roo environ aussi bien chez le ray-grass que chez le dactyle. Les tiges étant plus riches en membranes qui sont elles-mêmes plus lignifiées (JARRIGE, I963), leur digestibilité diminue plus rapidement que celle des limbes (TILLEY, Ig6I; PRITCHARD et al., I963). La digestibilité des inflorescences peut également diminuer de façon rapide (PRITCHARD et al., I963), parce qu'elles ont des membranes aussi lignifiées que celles des tiges et particulièrement riches en xylanes (WAITE et GORROD, I959; JARRIGE, Ig63) qui sont les polysaccharides les moins digestibles.

Le degré de lignification des membranes explique également pourquoi les polysaccharides membranaires des repousses d'été et d'automne sont moins digestibles que ceux des plantes du premier cycle ayant la même composition morpho logique (fig. 5 et 6 ) : les membranes de ces repousses sont en effet plus lignifiées que celles du premier cycle. De même, c'est parce qu'elles sont plus lignifiées que les membranes du dactyle $\mathrm{S} 37$ sont moins digestibles que celles du ray-grass $\mathrm{S} 24$, à concentration égale dans le fourrage.

2) La digestibilité des polysaccharides de la membrane peut ne pas dépendre exclusivement đu degré de lignification; ainsi elle continue à décroître rapidement à la fin du premier cycle de croissance alors que la teneur en lignine augmente rela. tivement peu, tout au moins chez le ray-grass. Elle présente aussi une liaison négative étroite avec la concentration même de ces polysaccharides dans la plante (tabl. I5) : tout se passe comme si la teneur en polysaccharides membranaires digestibles du ray-grass $\mathrm{S} 24$ et du dactyle $\mathrm{S} 37$ ne pouvait guère dépasser $3^{\circ} \mathrm{p}$. I00, valeur qui représenterait ainsi la capacité digestive maximum de la population microbienne du rumen. Cela ne veut pas dire pour autant que la teneur des polysaccharides agit sur leur digestibilité puisque elle évolue rigoureusement dans le même sens que la tenettr en lignine. Il est vraisemblable que celle-ci a un rôle beaucoup plus important puisque la digestibilité de la cellulose des fourrages peut être augmentée par la délignification (FERGUSON, I942) ou par un broyage très fin. (DEHORITY et JoHnson, Ig6I).

3) On pourrait également penser que la digestibilité des polysaccharides membranaires dépend dans une certaine mesure de leurs caractéristiques physico-chimiques (degré de polymérisation - degré de cristallinité...), et en voir une preuve dans le fait que les polysaccharides de la membrane n'ont pas tous la même digestibilité. La digestibilité plus faible des xylanes semble être générale chez les Graminées : depuis que nous l'avons signalée (JARRIGE, I960) elle a été observée, à l'aide de méthodes analytiques sensiblement différentes, sur des échantillons de ray-grass $S 23$ (WAITE, et al., I962), de dactyle et de fléole (WAITE et al., I963), d'herbe de prairies fraîche ou déshydratée, de foin et de seigle vert (GAILIARD, Ig63). Il n'est cependant pas possible d'en conclure que les xylanes sont en eux-mêmes plus résistants que les autres polysaccharides de la membrane à l'action des enzymes microbiens, car d'autres explications aussi hypothétiques peuvent être proposées : les xylanes pourraient être par exemple proportionnellement plus abondants dans les membranes des tissus lignifiés que dans celles des tissus cellulosiques ; ils pourraient également être mieux protégés que les autres polysaccharides par la lignine ou même présenter des liaisons chimiques plus étroites avec celle-ci : de telles liaisons semblent bien exister tout au moins dans les bois (cf. Merewether, I 960 ).

On manque de données expérimentales permettant d'estimer l'influence réelle des caractéristiques physico-chimiques des polysaccharides membranaires sur leur

Annales de Zootechnie. - I964. 
digestibilité, et de la séparer de l'influence de la lignification qui varie simultanément. Le degré de polymérisation de la cellulose n'aurait pas d'action (Françors, I954; BAKER et al., I959) mais le degré de cristallinité pourrait en avoir une (BAKER et al., I959). Dans l'état actuel de nos connaissances, on peut admettre que les polysaccharides membranaires ont une digestibilité qui dépend avant tout du degré de lignification et qui serait presque totale si les enzymes microbiens pouvaient arriver à leur contact dans tous les tissus de la plante.

Il est possible enfin que la digestibilité des membranes de certains échantillons dépende dans une certaine mesure de la concentration en constituants cytoplasmiques (matières azotées...) nécessaires à l'activité maximum de la population microbienne du rumen. Ce pourrait être le cas à la fin du premier cycle de croissance car la digestibilité des polysaccharides membranaires diminue très rapidement alors que la teneur et la composition des membranes évoluent relativement peu.

Quoiqu'il en soit, la digestibilité des polysaccharides membranaires détermine la digestibilité de la matière organique et par suite la valeur énergétique nette des plantes fourragères : les mesures calorimétriques effectuées récemment par ARMSTRONG (I960-I963) sur des échantillons de ray-grass S 23, de ray-grass S 24, de dactyle S 37 et de fléole $S_{48}$, confirment bien que la perte d'énergie fécale est le facteur prépondérant de la valeur énergétique nette de ces fourrages pour le mouton. Cependant l'utilisation de 1'énergie digestible peut varier dans certains cas avec les proportions relatives des différents produits terminaux de la digestion (glucose-acides gras volatils...) : l'acide acétique est ainsi moins bien utilisé que les acides propionique, butyrique ou lactique et que le glucose pour l'engraissement (BLAXTER, I962). La composition du mélange d'acides gras volatils présent dans le rumen peut varier avec la composition de la plante ou, mieux encore, avec la composition de la matière organique digestible qui est le milieu de prolifération de la population microbienne du rumen ; nos résultats à cet égard (fig. 9 et Io) permettent de mieux comprendre pourquoi la proportion d'acide acétique dans le mélange d'acides gras volatils peut augmenter quand la teneur en membranes augmente et que la digestibilité diminue (cf. BLAXTER, I962).

Cette influence est généralement renforcée par les variations de la teneur en glucides solubles qui sont encore plus importantes lorsqu'on exprime celle-ci en pourcentage de la matière organique digestible. Ces différences systématiques dans la composition de la matière organique digestible doivent expliquer pourquoi la fermentation in vitro des échantillons de ray-grass produit une proportion plus élevée d'acide propionique que celle des échantillons de dactyle correspondants (TILIEY et al, ig60). De tels mécanismes pourraient expliquer dans une certaine mesure les variations du taux butyreux avec la nature du pâturage, observées par JARRIGE et JoURNET (I959) et par DEMARQUILLY (Ig63).

Reçu pour publication en février 1964 .

\section{SUMMARY}

CHEMICAL COMPOSITION AND DIGESTIBILITY OF S 24 RYEGRASS AND S 37 COCKSFOOT WITH SPECIAL REFERENCE TO TIE CARBOHYDRATE CONSTITUENTS

I) The object of this study was to determine reasons for the differences in the digestibility of S 24 ryegrass and S 37 cocksfoot which Minson, RAYMOND and HARRIs (I960) could not account for by differences in leaf lamina percentage (fig. I). Sclected samples of feed and faeces were obtained 
from these authors for further study. The contents and digestibilities of the principle carbonydrate fractions were measured with special reference to the polysaccharides of the cell wall.

Determinations were made on 30 samples of $S_{24}$ ryegrass (i 7 first growths, ${ }_{3} 3$ regrowths), 32 samples of $\mathrm{S} 37$ cocksfoot (I 9 first growths, 13 regrowths) and 62 samples of the corresponding sheep faeces for the following fractions; ash, protein, alcohol-benzene extract, water soluble carbohydrates hemicellulose, cellulose and corrected lignin (JARRIGE, I961). The sum of all these determinations represented 84 percent of the herbage dry matter and 86 percent of the faeces dry matter. All sam ples were also analysed for crude fibre and lignocellulose.

Using paper chromatography the monosaccharide content of the cell wall polysaccharides was determined on 8 ryegrass, 8 cocksfoot and the corresponding faeces samples.

2) The detailed chemical composition of the 62 forages are shown in tables $\mathrm{I}-4$. The proportion of leaf was the principle factor controlling the protein content of these samples (fig. 2). 'The soluble carbohydrate content showed very large differences $(\mathrm{I}, 6-2 \mathrm{I}, 5$ percent) related to stage of growth, year and herbage species.

There was an inverse relationship between hemicellulose, cellulose and lignin on the one hand and leaf percentage on the other (fig. 3 and 4). In regrowths the contents of hemicellulose, cellulose and lignin were higher than for first growths with similar leaf percentages. The contents of lignocellulose and crude fibre showed a highly significant correlation with the cellulose + lignin content (table I I).

Cellulose (I4-28 percent) and xylans (8-i6 p. I00) were the more variable fractions; 88,5 p. I00 of the xylans were recovered in the hemicellulose fraction (tables 9 and 10 ). The contents of hydro lysable hexosans and arabans were relatively low and less variable than the xylans contents.

Ryegrass contained more soluble carbohydrate than cocksfoot but less cellulose and lignin.

3) The different carbohydrate constituents did not have the same digestibilities (tables $5^{-8}$ ). The soluble carbohydrates are completely digested. The digestibility of the lignin was usually between - I 5 and + I 5 p. Ioo.

The cellulose digestibility varied from $46 \mathrm{p}$. Ioo for mature cocksfoot to $97 \mathrm{p}$. 1oo for young ryegrass. The hemicellulose was usually $9-6$ units less digestible than the cellulose in the same samples. The xylans in the cell wall were less digestible than the arabans and hexosans (tables 9 and ro).

There were negative correlations between the digestibilities of the hemicellulose and cellulose fractions and their respective concentrations in the herbage (table 15). As a result of this inverse relationship the quantity of digestible cell wall polysaccharides (digestible hemicellulose + digestible cellulose) showed only small variations; it was between 25 and $3^{\circ} \mathrm{p}$. Ioo of the dry matter of both ryegrass and cocksfoot at all stages of growth (fig. 7 and 8).

4) The digestibility of the cell wall polysaccharides showed a highly significant negative correlation $(r=0,95)$ with the lignin content. Also the quantity of indigestible cell wall polysaccharide (indigestible hemicellulose and cellulose) was proportional to the quantity of lignin in the herbage (fig. 12). This relationship applied to both first growths and regrowths of ryegrass and cocksfoot.

Although the degree of lignification is shown to be a major factor limiting the availability of cell wall polysaccharides it is possible that this is also limited by a decline in the digestibility of the cell wall polysaccharides per se.

5) The digestibility of the organic matter of the plant depends mainly on the digestibility of the cell wall polysaccharides (table i4, fig. I1). IIence the high digestibility of both ryegrass and cocksfoot up to ear emergence and the higher overall digestibility of ryegrass. Another reason for the high digestibility of ryegrass was the high content of soluble carbohydrate by comparison with cocksfoot.

6) There were variations in the compositions of the digestible organic matter both between years within species and between species (fig. 9 and 10). The soluble carbohydrate content was the most variable, ranging from 3 to $3^{\circ} \mathrm{p}$. 100 .

\section{RÉFÉRENCES BIBLIOGRAPHIQUES}

Armstrong D. G., I960. Calorimetric determination of the net energy value of dried $\mathrm{S} 23$ rye-grass at four stages of growth. Proc. 8th Internat. Grassl. Congr., 485-489.

Armstrong D. G., I963. Net energy values for artificially dried rye-grass, cocksfoot and timothy. Proc. Nutr. Soc., 22, XXV.

BAKER F., Harriss S. T., I947. Microbial digestion in the rumen (and caecum), with special reference to the decomposition of structural cellulose. Nutr. Abs. Rev., 3-12.

Baker T. I., Bentley G. V., Bentley O. G., Johnson R. R., Moxon A. L., i959. The influence of 
certain physical properties of purified celluloses and forage celluloses on their digestibility by rumen microorganisms in vitro. J. Anim. Sci., 18, 655-662.

BAti I. H., RooK J. A. F., x $196 \mathrm{r}$. The effect of stage of growth of $\mathrm{S} 23$ perennial rye-grass on the production of volatile fatty acids in the rumen of the cow. Proc. Nutr. Soc., 20, XV.

BLAXTER K. L., 1962. The energy metabolism of numinants. Hutchinson Ed.

Crampton E. W., Maynard L. A., 1938. The relation of cellulose and lignin content to the nutritive value of animal feeds. $J$. Nutr., 15, $3^{8} 3^{-395}$.

Defority B. A., Johnson R. R., I $96 \mathrm{r}$. Effect of particle size upon the in vitro cellulose digestibility of forages by rumen bacteria. J. Dairy Sci., 44, 2242-2249.

Demarquilly C., I963. Influence de la nature du pâturage sur la production laitière et la composition du lait. Ann. Zootech., 12, 69-104.

Dijkstra N. D., Brandsma S., i955. Research into the digestibility and feeding value of fresh lucerne. Versl. Landbouzok Onderz., 61 (5).

Drapala W. J., Raymond L. C., Crampton E. W., I947. Pasture studies. XXVII. The effects of pasture maturity of the plant and its lignification on subsequent digestibility by animals as indicated by method of plant histology. Sci. Agr., 27, 36-41.

Françors A. C., i954. Corrélation entre le taux de lignine, le taux de cellulose et le degré de polymérisation de la cellulose de la luzerne. Contérence Européenne des Herbages. Projet no 224 O. E. C. E., 299-301.

FERguson W. S., I942. The digestibility of wheat straw and wheat straw pulp. Biochem. J., 36, 786.

Gaillard Blanche D. E., I 962 . The relationship between the cell-wall constituents of roughages and the digestibility of the organic matter. J. Agric. Sci., 59, 369-373.

HoLTER J. A., REID J. T., I959. Relationship between the concentrations of crude protein and apparently digestible protein in forages. J. Anim. Sdci., 18, г $339^{-1} 349$.

Hомв T., 1953. Chemical composition and digestibility of grassland crops. Acla Agric. Scand., 3, 1-32.

JARrige R., Journet M., 1959. Production laitière et pâturage des prairies temporaires. Bull. Tech. Inform., 145, 697-7IS.

JARrige R., 1960. The membrane constituents of herbage. Proc. 8th Internat. Grassl. Congr., 628-635.

JARRIGE R., ig6r. Analyse des constituants glucidiques des plantes fourragères. r. Fractionnement des membranes par les hydrolyses acides. Ann. Biol. anim. Bioch. Biophys., 1, I63-21 2.

JARRIGE R., 1953. Les constituants membranaires des plantes fourragères. Ann. Biol. anim. Bioch. Biophys., 3, I $43^{-1} 9^{\circ}$.

JouRneT M., Jarrige R., I 962. Analyse des constituants glucidiques des plantes fourragères. III. Études sur le dosage de la lignine. Ann. Biol. anim. Bioch. Biophys., 2, 223-250.

KivimaE A., 1959. Chemical composition and digestibility of some grassland crops. Acta Agric. Scand., 9, Sup. I 42 p.

Merewetier J. W. T., i960. The linkage of lignin in the plant. In Brauns et Brauns : The Chemistry of lignin. Supplement volume (Academic Press), p. 630-658.

Mrnson D. J., Raymond W. F., Harris C. E., rg6o. Studies in the digestibility of herbage. VIII. The digestibility of $\mathrm{S} 37$ cocksfoot, $\mathrm{S} 23$ rye-grass and $\mathrm{S}_{24}$ rye-grass. J. Brit. Grassl. Soc., 15, 1 74 -180.

Pritchiard G. I., Folkins L. P., Pigden W. J., 1963. The in vitro digestibility of whole grasses and their parts at progressive stages of maturity. Canad. J. Plant. Sci., 43, 79-87.

REGAL V., 1960. The evaluation of the quality of pasture grasses by the microscopic method. Proc. 8th Internat. Grassl. Congr., 522-524.

Somogyr M., 1952. Notes on sugar determination. J. Biol. Chem., 195, 19-23.

Trlley M., I961. Études in vilro de la digestion des fourrages. Ann. Nutr. Alim., 15, 267-272.

TIlley J. M. A., DeRIAZ R. E., TERRY R. A., 1960. The in vitro measurement of herbage digestibility and assessment of nutritive value. Proc. 8th Internat. Grassl. Congr., 533-537.

Watte R., Gorrod A. R. N., I959. The structural carbohydrates of grasses. J. Sci. Fd. Agric., 10, 308-317.

Watte R., Johnson M. J., Armstrong D. G., Ig62. The digestibility of the carbohydrate constituents of $\mathrm{S} 23$ rye-grass cut at four stages of growth. Proc. Nutr. Soc., 21, XXI.

Waite R., Johnson M. J., ARmstrong D. G., 1963. The digestibility of the carbohydrate constituents of artificially dried rye-grass, cocksfoot and timothy at various stages of growth. Proc. Nutr. Soc., 22, XXIV. 